\title{
Effects of Wave-Current Interactions on Suspended-Sediment Dynamics during Strong Wave Events in Jiaozhou Bay, Qingdao, China ${ }^{\mathscr{O}}$
}

\author{
Guan Dong Gao, ${ }^{\mathrm{a}, \mathrm{b}, \mathrm{c}}$ Xiao Hua Wang,${ }^{\mathrm{c}, \mathrm{d}}$ Dehai Song,,${ }^{\mathrm{e}, \mathrm{b}}$ Xianwen Bao, ${ }^{\mathrm{e}, \mathrm{b}}$ BaO Shu Yin, ${ }^{\mathrm{a}, \mathrm{b}, \mathrm{f}}$ \\ De Zhou Yang, ${ }^{\mathrm{a}, \mathrm{b}}$ YANG Ding, ${ }^{\mathrm{e}, \mathrm{b}}$ HaOQIAN Li, ${ }^{\mathrm{g}}$ FANG Hou, ${ }^{\mathrm{h}}$ AND ZHAOPENG ReN ${ }^{\mathrm{i}}$ \\ ${ }^{a}$ Key Laboratory of Ocean Circulation and Waves, Institute of Oceanology, Chinese Academy of Sciences, Qingdao, China \\ ${ }^{\mathrm{b}}$ Qingdao National Laboratory for Marine Science and Technology, Qingdao, China \\ ${ }^{\mathrm{c}}$ Sino-Australian Research Centre for Coastal Management, University of New South Wales Canberra, Canberra, \\ Australian Capital Territory, Australia \\ ${ }^{\mathrm{d}}$ School of Physical, Environmental and Mathematical Sciences, University of New South Wales Canberra, Canberra, \\ Australian Capital Territory, Australia

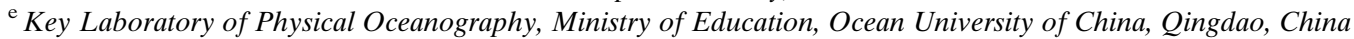 \\ ${ }^{\mathrm{f}}$ University of Chinese Academy of Sciences, Beijing, China \\ ${ }^{\mathrm{g}}$ North China Sea Marine Forecasting Center, State Oceanic Administration, Qingdao, China \\ ${ }^{\mathrm{h}}$ National Environment Forecast Center, Beijing, China \\ ${ }^{\mathrm{i}}$ Meteorological Bureau of Qingdao, Qingdao, China
}

(Manuscript received 12 December 2017, in final form 16 March 2018)

\begin{abstract}
Wave-current interactions are crucial to suspended-sediment dynamics, but the roles of the associated physical mechanisms, the depth-dependent wave radiation stress, Stokes drift velocity, vertical transfer of wave-generated pressure transfer to the mean momentum equation (form drag), wave dissipation as a source term in the turbulence kinetic energy equation, and mean current advection and refraction of wave energy, have not yet been fully understood. Therefore, in this study, a computationally fast wave model developed by Mellor et al., a Finite Volume Coastal Ocean Model (FVCOM) hydrodynamics model, and the sediment model developed by the University of New South Wales are two-way coupled to study the effect of each wave-current interaction mechanism on suspended-sediment dynamics near shore during strong wave events in a tidally dominated and semiclosed bay, Jiaozhou Bay, as a case study. Comparison of Geostationary Ocean Color Imager data and model results demonstrates that the inclusion of just the combined wave-current bottom stress in the model, as done in most previous studies, is clearly far from adequate to model accurately the suspended-sediment dynamics. The effect of each mechanism in the wave-current coupled processes is also investigated separately through numerical simulations. It is found that, even though the combined wave-current bottom stress has the largest effect, the combined effect of the other wave-current interactions, mean current advection and refraction of wave energy, wave radiation stress, and form drag (from largest to smallest effect), are comparable. These mechanisms can cause significant variation in the current velocities, vertical mixing, and even the bottom stress, and should obviously be paid more attention when modeling suspended-sediment dynamics during strong wave events.
\end{abstract}

\section{Introduction}

Understanding suspended-sediment dynamics is crucial to marine engineering projects, the maintenance of navigation channels, geomorphological development, and the availability of light for marine primary production. It is well known that wave-current interactions

Supplemental information related to this paper is available at the Journals Online website: https://doi.org/10.1175/JPO-D-17-0259.s1.

Corresponding author: Dehai Song, songdh@ouc.edu.cn are of great importance to nearshore hydrodynamics at regional scales (Longuet-Higgins and Stewart 1964; Smith 2006; Sheng and Liu 2011) and consequently to suspended-sediment dynamics (Graber et al. 1989; Porter-Smith et al. 2004; Dufois et al. 2014).

The wave-current interactions generally consist of combined wave-current bottom stress, wave radiation stress, wave dissipation, vertical transfer of wavegenerated pressure transfer to the mean momentum equation (also known as form drag), Stokes drift velocities, current advection, and refraction of wave energy (Mellor 2003; Mellor et al. 2008; Mellor 2015). The 
role of waves in suspended-sediment dynamics has already been extensively studied through numerical simulations of locations all over the world, and especially those suffering from wind storms and hurricanes (e.g., Lou et al. 2000; Palanques et al. 2011; Dufois et al. 2014). However, almost all the studies focused only on one or several of the wave-current interaction terms rather than the combined effects of all of them. Specifically, numerous studies (e.g., Tang and Grimshaw 1996; Lou et al. 2000; Wang et al. 2000; Wang et al. 2007) have investigated the impact of waves on suspendedsediment dynamics solely through the bottom stress induced by wave orbital velocities near the bottom and its interaction with the current-induced bottom stress (the combined wave-current bottom stress), but few studies have included the other wave-current interaction terms. Dufois et al. (2014) used wave radiation stress derived from the simulating waves nearshore (SWAN) model as the wave forcing to study the impact of winter storms on the resuspension and transport of sediments in the Rhone River prodelta and the Gulf of Lion. Their model investigated how the wave-induced currents generated by wave radiation stress affected the bottom stress but neglected the combined wave-current bottom stress. The physical mechanisms of current advection and refraction of wave energy have been even less well studied in previous work, as the wave model adopted was mostly run without current information (e.g., Lou et al. 2000; Wang et al. 2000; Wang et al. 2007). Based on the Regional Ocean Modeling System (ROMS) and SWAN, Warner et al. (2008) developed a two-way coupled wave-current-sediment model in which the combined wave-current bottom stress, wave radiation stress, current advection, and refraction of wave energy were included. To the authors' knowledge, this is the most comprehensive study modeling the effects of wavecurrent interactions on suspended-sediment dynamics, but wave dissipation related to wave breaking and the form drag proposed by Mellor $(2003,2005)$ were still not considered. The study of Warner et al. (2008) focused on the development and application of a coupled wavecurrent-sediment model, but the role and contribution of each wave-current interaction mechanism were not examined.

Most of the studies cited above on sediment transport under conditions of strong waves used one-way coupling between the hydrodynamics model and the wave model, simply providing the wave parameters derived from the wave model to the hydrodynamics model to improve computational efficiency; the effects of mean current advection and refraction of wave energy were therefore not included (e.g., Lou et al. 2000; Wang et al. 2000). If two-way interactions between the wave and current models were included, enormous computation resources would be required, as community wave models such as SWAN and WAVEWATCH III normally need several orders of magnitude more computational time than hydrodynamics models. Hydrodynamics models use four independent variables: two horizontal coordinates $x, y$; a vertical coordinate $z$; and time $t$. Wave models use five independent variables: two spatial coordinates $x, y$; time $t$; the wave propagation angle $\theta$; and frequency $\sigma$. Considering frequency as the additional variable with, for example, 30 numerically discrete frequency bins and also the time needed for computation of the nonlinear wave-wave interaction and the integration of various properties including the new coupling terms, the computation effort required would be increased by around two orders of magnitude compared with the hydrodynamics model alone (Mellor 2003; 2005). Taking the Princeton Ocean Model (POM) as an example, for the same horizontal grid and time length of run, the SWAN model required 86 times more computational time than the hydrodynamics model (Mellor et al. 2008). One-way coupling is efficient in terms of computational time, but the results are less accurate since the wave model does not receive synchronous feedback from the hydrodynamics model, and so fails to consider the physical processes of current advection and refraction of wave energy.

To solve this problem, Mellor et al. (2008) developed a faster wave model [Mellor-Donelan-Oey wave model (MDO-Wave)], which can be coupled with a threedimensional hydrodynamics model. The coupling between waves and currents includes depth-dependent wave radiation stress, Stokes drift velocities, vertical transfer of wave-generated pressure transfer to the mean momentum equation caused by form drag, wave dissipation as a source term in the turbulence-kineticenergy equation, and mean current advection and refraction of wave energy (Mellor 2003; Mellor et al. 2008; Mellor 2015). This wave model has already been well validated in theoretical experiments and successfully applied in many regions such as the Gulf of Mexico (Mellor et al. 2008) and Liverpool Bay (Bolaños et al. 2014) as well as in an oil-spill model (Wang and Shen 2012). Sheng and Liu (2011) found the method of Mellor et al. (2008) to be more accurate than alternative 3D methods at hindcasting wave-induced circulation. The Finite Volume Coastal Ocean Model (FVCOM), which employs unstructured grids, can resolve the complex bathymetric features in nearshore areas and is two-way coupled with MDO-Wave in this study to consider all the wave-current interaction terms. The University of New South Wales sediment model (UNSW-Sed; Wang 2002) has been successfully applied in many regions such as the northern Adriatic Sea (Wang et al. 2007), the 

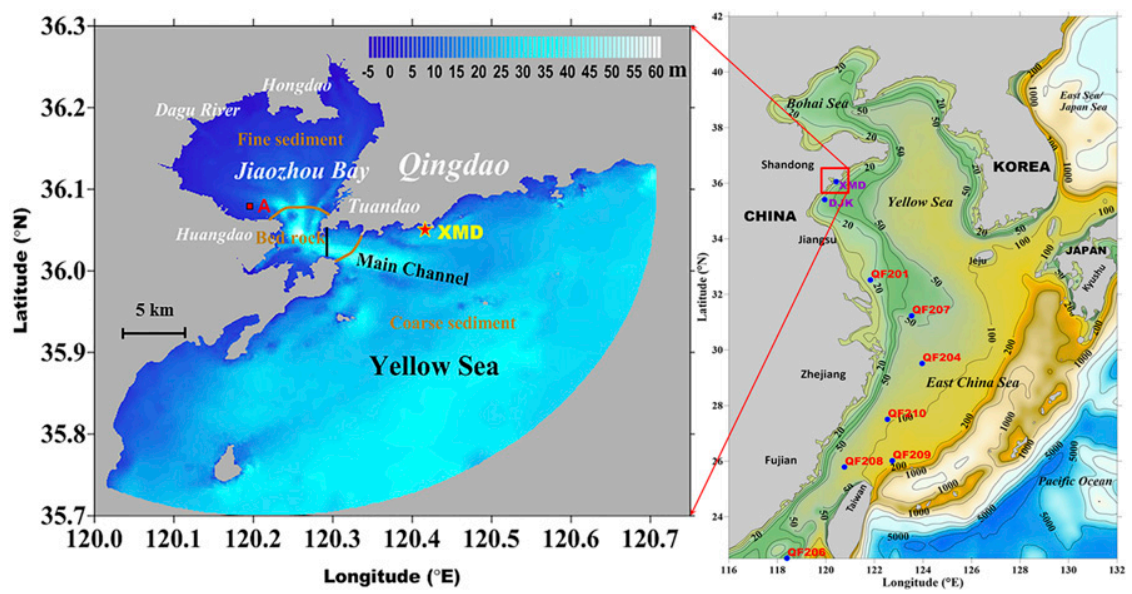

FIG. 1. Bathymetry map of JZB, Qingdao, in 2008 showing the model domain. (left) Measurements of winds and waves at station XMD are used to validate the wave model in JZB, and (right) measurements at station DJK to validate the wave model near the open sea. A northsouth line in the main channel divides JZB from the YS. Model results from station A (red square) are used for the discussions in sections $4 \mathrm{~b}-4 \mathrm{f}$. According to the types of bed sediment, the model domain of JZB is divided into three regions by the brown lines: JZB excluding its main entrance (fine sediment), the main entrance (bedrock), and the adjoining sea areas (coarse sediment). Locations of wave buoys in the ECS are shown by the red dots in (right).

Yangtze River Estuary in China (Song and Wang 2013), Darwin Harbour in Australia (Li et al. 2014), and Jiaozhou Bay (Gao et al. 2018). Details of FVCOM, MDO-Wave, and UNSW-Sed, as well as the coupling between them, are given in section $3 \mathrm{a}$ and the appendix.

Jiaozhou Bay (JZB), located on the western coast of the Yellow Sea (YS), is a semienclosed bay dominated by tides with mean ranges of about $2.7 \mathrm{~m}$. The bed of JZB is mostly fine sediments, which are the primary source of the suspended sediments in the bay. During cold-front events, strong waves propagate from the YS into JZB, leading to a significant interaction between the waves and currents and consequently a significant impact on the suspended sediments. Hence, JZB is a good location at which to examine the roles and contributions of each wave-current interaction mechanism to the suspended-sediment dynamics; the findings in JZB should also be applicable to other coastal areas experiencing strong wave-current interactions.

The specific aims of this study are the following: 1) based on FVCOM, MDO-Wave, and UNSW-Sed, to set up a two-way coupled wave-current-sediment model that considers all the wave-current interaction mechanisms, each mechanism represented by an equation or a term in an equation; and 2) to investigate the relative contribution and role of each wave-current interaction mechanism to the suspended-sediment dynamics.

Section 2 gives a brief description of the study area, JZB. Details of the coupled wave-current-sediment model are given briefly in section 3 and fully in the appendix. Section 4 presents the model results and discussion, with a summary and conclusions in the last section.

\section{Study area}

JZB is a shallow semienclosed embayment with an average depth of about $7 \mathrm{~m}$ and an area of about $340 \mathrm{~km}^{2}$. It is connected to the YS through a deep tidal channel with a depth of more than $60 \mathrm{~m}$ (Fig. 1). The tidal channel has a minimum width of $3 \mathrm{~km}$.

The hydrodynamics environment in JZB is controlled by semidiurnal tides, with a moderate tidal range of about $2.7 \mathrm{~m}$. The tides in JZB are flood dominated, the current velocities are higher during flood than during ebb, and the degree of flood domination has varied with land reclamation (Gao et al. 2014). The annual average wind speed is $5.4 \mathrm{~m} \mathrm{~s}^{-1}$ (Editorial Board of Annals of Bays in China 1993), and the waves in JZB are generally weak in calm weather. However, during cold-front events, strong waves can propagate from the YS into JZB (Fig. 2a). Observed wind speeds and directions at station XMD (Fig. 1) are shown in Figs. 2c and 2d. The resulting wave orbital velocities near the bottom became large in the shallow-water areas, especially the tidal flats in JZB (Fig. 2b).

\section{Numerical modeling}

\section{a. The wave model}

In this study, the wave model MDO-Wave was coupled with the hydrodynamics model FVCOM. MDO-Wave 

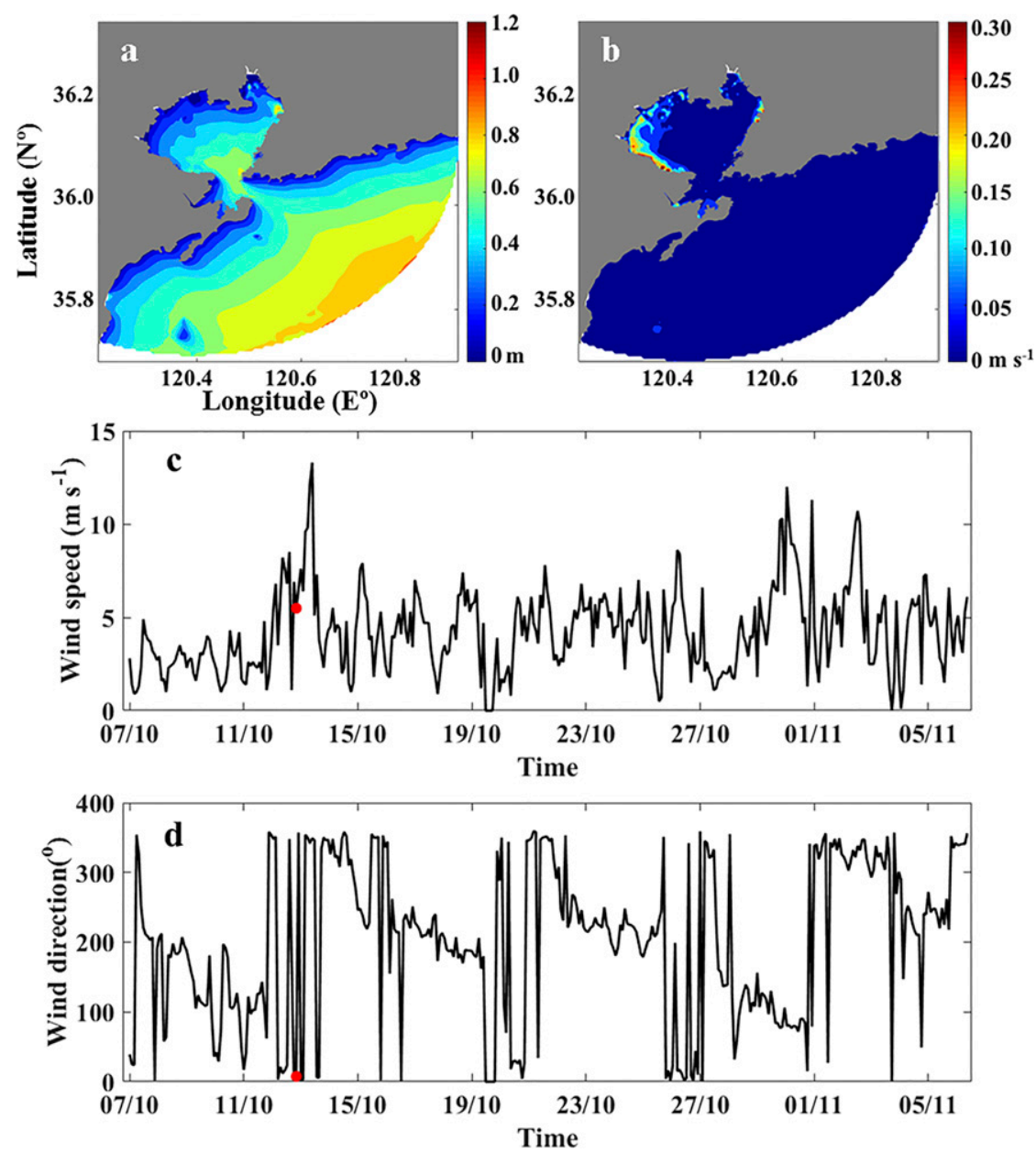

FIG. 2. Snapshot of (a) significant wave heights and (b) wave orbital velocities near the bottom in a cold-front wave event (0130 UTC 13 Oct 2014) in JZB. Time series of (c) wind speeds and (d) directions observed at station XMD. Red dots indicate the time of 0130 UTC 13 Oct 2014.

parameterizes the shape of the frequency spectrum (Donelan et al. 1985) and considers the wave energy as a function of the wave propagation direction, the horizontal coordinates, and time, with the wave frequency dependent on direction rather than being an independent variable. It is, therefore, a relatively simple model compared with third-generation wave models, and computationally more efficient, requiring two orders of magnitude less computational resources. Moreover, Mellor et al. (2008) showed that it could reproduce fetch- and duration-limited data and had comparable performance to SWAN (Booij et al. 1999) using buoy data taken during Hurricane Katrina.

A complete set of the equations and other theory underpinning the model used here are given in the appendix, with the variables and parameters defined in Table 1. The coupling of MDO-Wave into FVCOM and its theoretical validation are given in the supplemental material.

\section{b. Model setup}

The hydrodynamics, wave, and sediment models were run concurrently with two-way interaction on the same unstructured grid (Fig. 3a). This grid has been used to study the tidal dynamics and suspended-sediment dynamics in JZB in our previous studies (Gao et al. 2014, 2018). The grid has high resolution in the channels and near the coast (Fig. 3a).

The hydrodynamics model was forced by tidal levels at the open boundary and a spatially uniform wind stress over the entire model domain (the same wind stress as for the wave model in JZB). Four diurnal components $\left(\mathrm{K}_{1}\right.$, $\left.\mathrm{Q}_{1}, \mathrm{P}_{1}, \mathrm{Q}_{1}\right)$, four semidiurnal components $\left(\mathrm{M}_{2}, \mathrm{~S}_{2}, \mathrm{~N}_{2}\right.$, $\left.\mathrm{K}_{2}\right)$, three shallow-water components $\left(\mathrm{M}_{4}, \mathrm{MS}_{4}, \mathrm{MN}_{4}\right)$, 
TABLE 1. List of the symbols used in the coupled wave-current-sediment model ("_-" means nondimensional).

\begin{tabular}{|c|c|c|}
\hline Symbol & Description & Units \\
\hline$E_{\sigma, \theta}$ & Directional spectrum of kinematic energy divided by water density & $\mathrm{m}^{3} \mathrm{~s}^{-2}$ \\
\hline$E_{\theta}$ & Spectrally averaged wave energy divided by water density & $\mathrm{m}^{3} \mathrm{~s}^{-2}$ \\
\hline$E_{T}$ & Total wave energy divided by water density & $\mathrm{m}^{3} \mathrm{~s}^{-2}$ \\
\hline$\hat{\eta}$ & Water height above the mean & $\mathrm{m}$ \\
\hline$H$ & Mean water depth & $\mathrm{m}$ \\
\hline$D=H+\hat{\eta}$ & Total water column depth & $\mathrm{m}$ \\
\hline$x, y, z$ & East, north and vertical Cartesian coordinates & $\mathrm{m}$ \\
\hline$t$ & Time & $\mathrm{s}$ \\
\hline$\varsigma=(\hat{\eta}-z) / D$ & Sigma (vertical) coordinate & \\
\hline$u, v, w$ & Velocities in the $x, y$, and $z$ directions & $\mathrm{m} \mathrm{s}^{-1}$ \\
\hline$\sigma$ & Wave frequency & $\mathrm{s}^{-1}$ \\
\hline$\sigma_{p}$ & Peak wave frequency & $\mathrm{s}^{-1}$ \\
\hline $\mathbf{c}_{g}$ & Group velocity & $\mathrm{m} \mathrm{s}^{-1}$ \\
\hline u & Current velocity & \\
\hline $\mathbf{u}_{s}$ & Stokes drift velocity & \\
\hline $\mathbf{u}_{\alpha}$ & $\begin{array}{l}\text { The } \alpha \text { component of the current velocity } \mathbf{u} \text { plus the } \alpha \text { component of the Stokes drift } \\
\text { velocity } \mathbf{u}_{s}\end{array}$ & \\
\hline $\mathbf{u}_{A}$ & Doppler velocity & $\mathrm{m} \mathrm{s}^{-1}$ \\
\hline$c_{\theta}$ & Refraction speed of wave energy & $\mathrm{m} \mathrm{s}^{-1}$ \\
\hline$c$ & Phase speed of wave propagation & $\mathrm{m} \mathrm{s}^{-1}$ \\
\hline$\theta$ & Wave direction & rad \\
\hline$k$ & Wave number & $\mathrm{m}^{-1}$ \\
\hline $\mathbf{k}$ & Wave vector: $\mathbf{k}=k(\cos \theta, \sin \theta)$ & - \\
\hline$S_{\theta \text { in }}$ & Wave energy source term & $\mathrm{m}^{3} \mathrm{~s}^{-3}$ \\
\hline$S_{\theta \text { Sdis, }} S_{\theta \text { Bdis }}$ & Surface and bottom wave dissipations & $\mathrm{m}^{3} \mathrm{~s}^{-3}$ \\
\hline$S^{(1)}{ }_{\theta \text { Bdis }}$ & Bottom wave dissipation caused by wave-induced bottom friction & $\mathrm{m}^{3} \mathrm{~s}^{-3}$ \\
\hline$S_{\theta \text { Bdis }}^{(2)}$ & Bottom wave dissipation caused by depth-induced wave breaking & $\mathrm{m}^{3} \mathrm{~s}^{-3}$ \\
\hline$\Re$ & Additional source term in Eq. (4) & $\mathrm{s}^{-2}$ \\
\hline$f_{\mathrm{spr}}$ & Spreading function & - \\
\hline$f$ & Coriolis parameter & $\operatorname{rad~s}^{-1}$ \\
\hline$g$ & Gravitational acceleration & $\mathrm{m} \mathrm{s}^{-2}$ \\
\hline$F_{u}, F_{v}$ & Horizontal momentum diffusion terms & $\mathrm{m} \mathrm{s}^{-2}$ \\
\hline$\tau_{t x}, \tau_{t y}$ & Components of the turbulent-viscous part of the wind stress & $\mathrm{m} \mathrm{s}^{-2}$ \\
\hline$\tau_{p x}, \tau_{p v}$ & Form drag components & $\mathrm{m}^{2} \mathrm{~s}^{-2}$ \\
\hline$R_{x}, R_{y}$ & Wave radiation stress components & $\mathrm{m}^{2} \mathrm{~s}^{-2}$ \\
\hline$P_{w 0}$ & Wind pressure at the surface & $\mathrm{m}^{2} \mathrm{~s}^{-2}$ \\
\hline$\eta$ & Water elevation caused by the waves & $\mathrm{m}$ \\
\hline$E_{D}$ & Modified delta function & - \\
\hline$q^{2}, l$ & Turbulent kinetic energy and turbulent macroscale & $\mathrm{m}^{2} \mathrm{~s}^{-2}, \mathrm{~m}$ \\
\hline$K_{m}$ & Vertical eddy viscosity coefficient & $\mathrm{m}^{2} \mathrm{~s}^{-1}$ \\
\hline$A_{h}$ & Horizontal eddy viscosity coefficient & $\mathrm{m}^{2} \mathrm{~s}^{-1}$ \\
\hline$P_{b}$ & Buoyancy production term of turbulent energy & $\mathrm{m}^{2} \mathrm{~s}^{-3}$ \\
\hline$\varepsilon$ & Rate of dissipation of turbulent kinetic energy & $\mathrm{m}^{2} \mathrm{~s}^{-3}$ \\
\hline$\tilde{W}$ & Wall proximity function & - \\
\hline$\kappa$ & Von Kármán constant & - \\
\hline$F_{q}, F_{l}$ & Horizontal diffusion terms for the turbulent kinetic energy and macroscale & $\mathrm{m}^{3} \mathrm{~s}^{-3}$ \\
\hline$S_{m}$ & Stability function & - \\
\hline$u_{*}$ & Air friction velocity & $\mathrm{m} \mathrm{s}^{-1}$ \\
\hline$u_{\tau s}$ & Wind stress & $\mathrm{m}^{2} \mathrm{~s}^{-2}$ \\
\hline$l$ & Empirical length scale & $\mathrm{m}$ \\
\hline$z_{w}$ & Wave-related roughness height & $\mathrm{m}$ \\
\hline$H_{s}$ & Significant wave height & $\mathrm{m}$ \\
\hline$\tau_{w c}=\tau_{c}+\tau_{w m}$ & $\begin{array}{l}\text { Vector sum of the time average of the instantaneous shear stress of the current } \tau_{c} \text { and } \\
\text { the maximum shear stress associated with the wave } \boldsymbol{\tau}_{w m}\end{array}$ & $\mathrm{~m}^{2} \mathrm{~s}^{-2}$ \\
\hline$u *_{w c}, u *_{c}, u *_{w m}$ & Shear velocities corresponding to $\tau_{w c}, \tau_{c}$, and $\tau_{w m}$, respectively & $\mathrm{m} \mathrm{s}^{-1}$ \\
\hline$\theta_{w c}$ & Angle between the current and the wave & $\mathrm{rad}$ \\
\hline$f_{c w}$ & Wave and current friction factor & - \\
\hline$u_{b}$ & Bottom wave orbital velocity & $\mathrm{m} \mathrm{s}^{-1}$ \\
\hline
\end{tabular}


TABLE 1. (Continued)

\begin{tabular}{llc}
\hline \hline \multicolumn{1}{c}{ Symbol } & & \multicolumn{1}{c}{ Description } \\
\hline$k_{N}$ & Equivalent Nikuradse roughness of the bottom & $\mathrm{m}$ \\
$z_{0 b}$ & Bottom roughness length & $\mathrm{m}$ \\
$\delta_{w c}$ & Wave boundary layer thickness & $\mathrm{m}$ \\
$C$ & Suspended-sediment concentration & $\mathrm{mg} \mathrm{L}^{-1}$ \\
$C_{b}$ & Suspended-sediment concentration near the bottom & $\mathrm{mg} \mathrm{L}^{-1}$ \\
$w_{s}$ & Particle settling velocity & $\mathrm{m} \mathrm{s}^{-1}$ \\
$\rho$ & Seawater density & $\mathrm{kg} \mathrm{m}^{-3}$ \\
$\rho_{w}$ & Clear seawater density & $\mathrm{kg} \mathrm{m}^{-3}$ \\
$\rho_{s}$ & Sediment density & $\mathrm{kg} \mathrm{m}^{-3}$ \\
$C_{d}$ & Bottom-friction coefficient & - \\
$R_{f}$ & Flux Richardson number & - \\
$z_{b}$ & Near-bottom layer thickness & $\mathrm{m}$ \\
$E_{b}$ & Net suspended-sediment flux at the bottom due to erosion and deposition & $\mathrm{kg} \mathrm{m}^{-2} \mathrm{~s}^{-1}$ \\
$E_{0}$ & Erosion coefficient & $\mathrm{kg} \mathrm{m}^{-2} \mathrm{~s}^{-1}$ \\
$\tau_{c}$ & Critical stress for resuspension and deposition & $\mathrm{N} \mathrm{m}^{-2}$ \\
\hline
\end{tabular}

and two long-period components $\left(\mathrm{M}_{\mathrm{f}}, \mathrm{M}_{\mathrm{m}}\right)$ were used to calculate the tidal elevations at the open boundary; the harmonic constants were derived from the TPXO global model of ocean tides (available at http://volkov.oce.orst. edu/tides/tpxo8_atlas.html; accessed on 15 January 2016).

To best resolve suspended sediments in the bottom boundary layer (Wang 2002), 20 sigma layers (the symbol $\varsigma$ is used here instead of $\sigma$ to avoid confusion with the wave frequency) were used, with 4 logarithmically distributed layers near the surface ( $s=0.0,-0.018,-0.036,-0.071$ ), 5 logarithmically distributed layers near the bottom $(s=-0.929,-0.964,-0.982,-0.991,-1.0)$, and 11 evenly distributed layers in the middle with an s increment of 0.071 .

In the sediment model, we used fine silt with medium grain size of $0.03 \mathrm{~mm}$ as representative of the suspended sediments (Wang 2002; Li et al. 2014) in JZB and its adjoining sea areas. Although the sediment considered in the model was cohesive, the concentration was generally low $\left(<100 \mathrm{mg} \mathrm{L}^{-1}\right)$, so flocculation is not considered in this study; the grain size and settling velocity were taken to be constant in the model. In the shallow waters (depth generally less than $4 \mathrm{~m}$ ) in JZB, the suspended-sediment concentration (SSC) near the bottom is larger than $100 \mathrm{mg} \mathrm{L}^{-1}$ when waves are strong during the modeling period. However, the maximum SSC in these areas is still smaller than the critical SSC $\left(200 \mathrm{mg} \mathrm{L}^{-1}\right)$ for flocculation proposed by Mehta and McAnally (2008). Therefore, flocculation is not important during the modeling period of this study but could be important when waves are even larger to result in SSC higher than $200 \mathrm{mg} \mathrm{L}^{-1}$.

Fine sediments are distributed all over the JZB except at the entrance, where bedrock dominates (First Institute of Oceanography 1984; Zhong et al. 2001). Coarse sands and boulders are distributed near the channel in the sea adjoining JZB (Wang et al. 2014). Available suspended sediments in the adjoining sea areas are limited, with concentrations generally lower
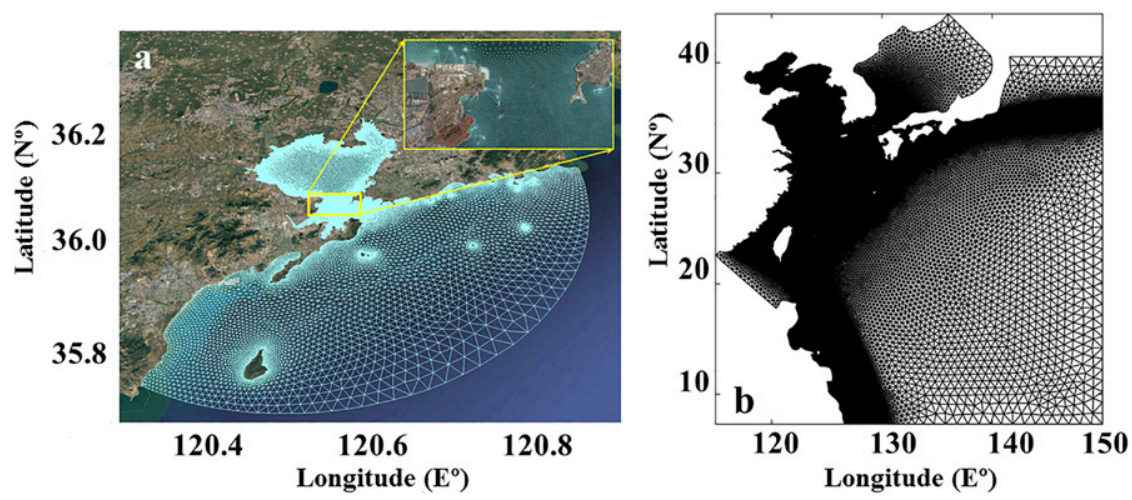

FIG. 3. Model mesh and grid distributions for (a) the coupled wave-current-sediment model in JZB and (b) the wave model in ECS. 
TABLE 2. Parameter settings in the sediment model.

\begin{tabular}{ll}
\hline \multicolumn{1}{c}{ Parameter } & \multicolumn{1}{c}{ Value } \\
\hline Medium grain size & $0.03 \mathrm{~mm}$ \\
Settling velocity & $0.4 \mathrm{~mm} \mathrm{~s}^{-1}$ \\
Erosion rate (Fig. 1) & Fine sediment: $6 \times 10^{-6} \mathrm{~kg} \mathrm{~m}^{-2} \mathrm{~s}^{-1}$ \\
& Bedrock: $1 \times 10^{-7} \mathrm{~kg} \mathrm{~m}^{-2} \mathrm{~s}^{-1}$ \\
& Coarse sediment: $2 \times 10^{-6} \mathrm{~kg} \mathrm{~m}^{-2} \mathrm{~s}^{-1}$ \\
Critical erosion stress & $0.04 \mathrm{~N} \mathrm{~m}^{-2}$ \\
Critical deposition stress & $0.02 \mathrm{~N} \mathrm{~m}^{-2}$ \\
\hline
\end{tabular}

than $10 \mathrm{mg} \mathrm{L}^{-1}$ (Yang et al. 2004). Therefore, the model domain was divided into three regions according to the fraction of fine sediments on the bed (Fig. 1): JZB excluding its main entrance (dominated by fine sediments); the main entrance (dominated by bedrock); and the adjoining sea areas (dominated by coarse sediments). The erosion rates used in the model for the suspended sediments were different for these three regions and adjusted to obtain the best model performance, as evaluated by comparison with observation and Geostationary Ocean Color Imager (GOCI) data [details in Figs. 3 and 5 in Gao et al. (2018)]. The model validation was conducted when waves were negligible, so the parameters obtained could reasonably characterize the suspended sediments governed by the tides. The other parameters of the sediment model developed by Gao et al. (2018) were also adopted here, and are given in Table 2. A comparison between the GOCI data and the model results from the coupled wave-currentsediment model when waves are significant is given in section $4 \mathrm{a}$.

The wind speed and direction (Figs. 2c,d) forcing the wave model in JZB were spatially uniform and were those observed $10 \mathrm{~m}$ above the sea surface at station XMD (Fig. 1) by the North China Sea Marine Forecasting Centre (NCSMFC) of the State Oceanic Administration (SOA). The wind observed at station XMD can represent the wind over the bay as it has a good agreement with the averaged wind recorded by other 13 automatic weather stations around JZB (not shown). To provide the wave forcing at the open boundaries of the JZB model, which are the swells coming from the YS, an unstructured-grid wave model [the East China Sea (ECS) wave model] covering the ECS was set up based on the SWAN wave model. The grid of the ECS wave model (Fig. 3b) was constructed by Ding et al. (2011) to study the barotropic response to a rapidly moving typhoon in the ECS. The grid has 100851 cells and 52685 nodes in total, with horizontal resolution varying from $0.02^{\circ}$ in nearshore regions to $1^{\circ}$ in the open ocean. The bathymetry data were obtained from the Digital Bathymetric Database 5 (DBDB5;

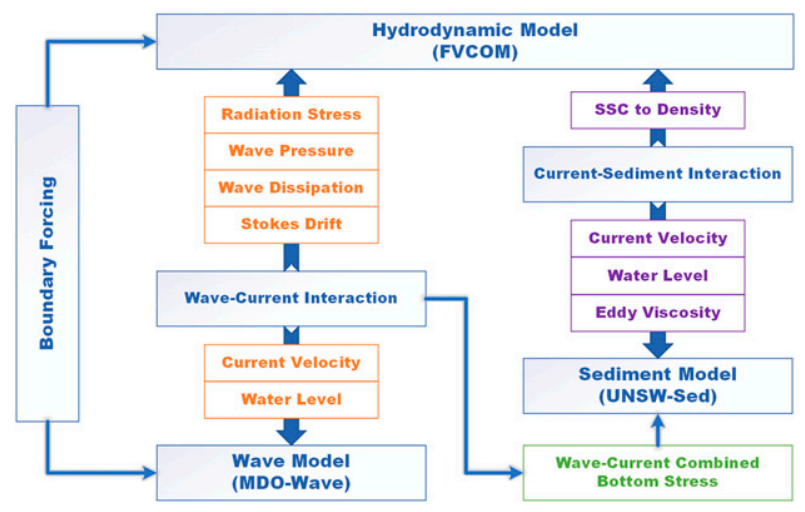

FIG. 4. Flowchart of the coupled wave-current-sediment model.

U.S. Naval Oceanographic Office 1983) and refined in the coastal areas using topography data from Chinese coastal sea charts. The ECS wave model was driven by sea surface wind $\left(6\right.$ hourly and a $0.205^{\circ} \times 0.204^{\circ}$ grid $)$ obtained from the National Centers for Environmental Prediction (NCEP) Climate Forecast System (CFS) (available at https://rda.ucar.edu/datasets/ds094.0/). The incoming waves at the open boundary were derived from WAVEWATCH III (available at http:// polar.ncep.noaa.gov/waves/).

Figure 4 shows the coupling process between the hydrodynamics, wave, and sediment models. The hydrodynamics model provided the instantaneous water levels and velocities to the wave model; the wave model fed back values of the three-dimensional wave radiation stress, form drag, Stokes drift velocities, wave dissipation, and combined wave-current bottom stress. Concurrently, the sediment model received water levels, current velocities, eddy viscosities, and combined wave-current bottom stress from the hydrodynamics model. The SSC calculated by the sediment model was provided to the hydrodynamics model to update the seawater density according to Eq. (23).

\section{c. Data and model validation}

The hydrodynamics/sediment model was used previously to study the effects of land reclamation on tidal dynamics in JZB (Gao et al. 2014) and on suspended-sediment dynamics when waves were negligible (Gao et al. 2018). The model was thoroughly calibrated and validated in these studies. For more details, see Gao et al. $(2014,2018)$.

In this section, we focus on the validation of wave simulation to ensure the contributions of waves are properly taken into account in the coupled wavecurrent-sediment model in JZB. The theoretical validation of the MDO-Wave model when it is coupled into FVCOM can be found in the supplementary material file. 
During cold-front events, strong waves from YS can enter JZB through the entrance, which was confirmed by numerical experiments (figure not shown here). Therefore, we collected wave data and ran the model for periods when cold-front events occurred. We obtained data from wave buoys (QF201, QF204, QF206, QF207, QF208, QF209, and QF210) distributed in the ECS by the SOA, China (see Fig. 1), for two periods (14 September1 October 2014 and 27 November-6 December 2014) to validate the ECS wave model. Wave data from station DJK (1-31 December 2014) provided by the Qingdao Meteorological Administration were used to validate the ECS wave model near the open boundary of the JZB model (Fig. 1). Wave data (7 November-13 December 2014) from station XMD acquired from the NSCMFC were used to validate the wave simulation of the coupled wave-current-sediment model in JZB. The ECS wave model was run for the four months from 1 September-31 December 2014 to cover the periods of observation of all the wave data. The coupled wavecurrent-sediment model in JZB was run for the period 7 October-13 December 2014. Results for one month starting from 12 October 2014 were chosen for analysis because peak wave heights occurred in JZB during this period.

The wave data collected here were significant wave heights and averaged wave periods. Figures 5 and 6 give a comparison between the model and observed significant wave heights and averaged wave periods from the wave buoys in the ECS over the two time periods. Root-mean-square errors (RMSEs) between the model and observation were calculated from a regression analysis; these are summarized in Table 3 . The significant wave heights given by the ECS wave model match the observations quite well; the errors in the averaged wave periods are relatively small, with the RMSEs at most stations less than $1 \mathrm{~s}$. The wave periods were often overestimated by the model, especially at buoys QF204, QF208, QF209, and QF210, probably owing to limitations in the spatial and temporal resolution of the wind data and in the spatial resolution of the bathymetry data. However, the wave periods at station DJK, located close to JZB (Fig. 1), were predicted better (Table 3). In summary, the swells propagating from the ECS to JZB were reliably reproduced by the ECS wave model. The overestimates of the wave periods at stations far away from JZB will not affect the conclusions in this study. The close agreement between the observed and modeled significant wave heights and averaged wave periods at station XMD (Fig. 1), shown in Fig. 7, validates the wave simulation during the strong wave events in JZB by the coupled wave-current-sediment model.

\section{Results}

In this section, we use the coupled wave-currentsediment model to evaluate the contributions to the suspended-sediment dynamics during strong wave events from six wave-current interaction mechanisms: 1) combined wave-current bottom stress, 2) wave dissipation, 3) pressure-slope momentum transfer by form drag, 4) wave radiation stress, 5) mean current advection of wave energy, and 6) mean current refraction of wave energy. The corresponding mathematical forms for these wave-current interaction mechanisms in the model are summarized in Table 4, and the full equations are given in the appendix. The Stokes drift velocities are included in the momentum equations when the wave-current interaction terms are present; Mellor (2005) claimed that it would be difficult and unnecessary to separate the Stokes drift velocities from the current velocities. Hence, in this study we will not discuss the effects of the Stokes drift velocities separately.

Current velocities are also involved in the last term on the left-hand side of Eq. (1), representing the energy exchange with the mean velocity energy equation. However, this term is negligible and is therefore omitted from the model; this term was not included in the wave-current interaction terms proposed by Mellor et al. (2008).

Eight numerical simulations were designed to evaluate the contributions from the different wave-current interaction terms; these simulations are summarized in Table 5. Simulation 1 is the control run, in which only currents were considered. In simulations 2 to 5 , the individual wave-current interaction terms 1 to 4 were added in turn to simulation 1 to investigate their contribution. Simulations 6 and 7 examine the contributions of the mean current advection of wave energy and the mean current refraction of wave energy, respectively, while simulation 8 contains all the wave-current interaction terms. The simulations are discussed in detail in sections $4 \mathrm{~b}$ to $4 \mathrm{f}$.

First, in the next section, we use the surface SSC (at a depth of around $0.5 \mathrm{~m}$ ), derived from GOCI data, to demonstrate the necessity of including more wavecurrent interaction mechanisms in the sediment model than just the combined wave-current bottom stress (simulation 2), as was done in most other studies (section 1); we compare simulation 2 and simulation 8 (all the wave-current interaction mechanisms included). Results from simulation 1 (current only) are also included in the comparison.

\section{a. Comparison between GOCI data and model results}

In 2010, a satellite with a GOCI covering the northeast Asian seas was launched by the Korea Ocean 

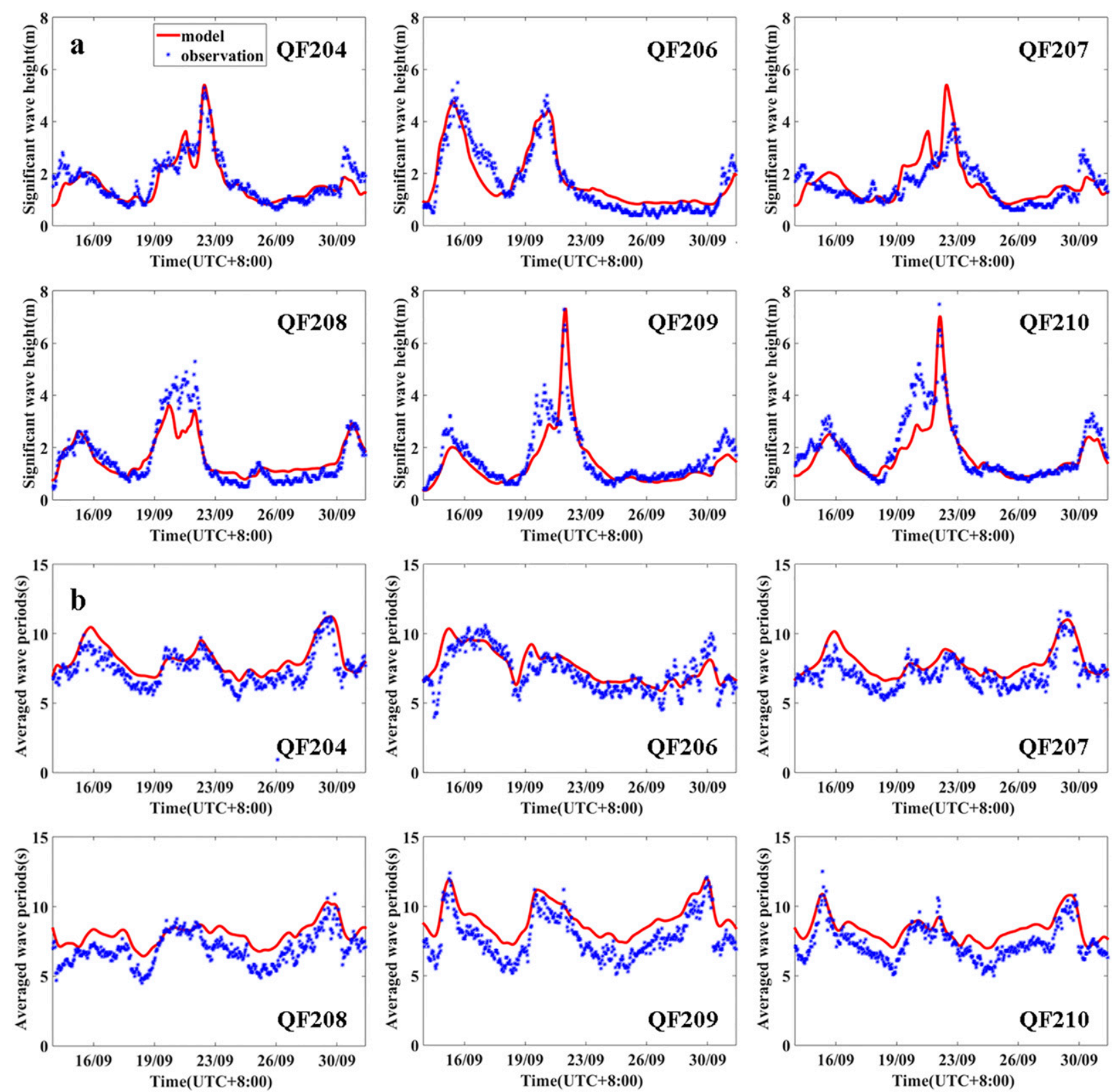

FIG. 5. Comparison of observed and modeled (top two rows) significant wave heights and (bottom two rows) averaged wave periods of the waves at the buoys in the ECS for the period 14 Sep to 1 Oct 2014.

Research and Development Institute. The sea surface sediment reflectance provided by the GOCI has a high horizontal resolution of $500 \mathrm{~m}$, measured over $8 \mathrm{~h}$ each day (at intervals of $1 \mathrm{~h}$ ) in the East China Sea and Sea of Japan (Choi et al. 2012; Ryu et al. 2012). The algorithm used here to calculate SSC from the GOCI data is that adopted by the official software GOCI Data Processing System (GDPS; Korea Ocean Satellite Center 2015) for coastal turbid waters:

$$
\log C=C_{0}+C_{1} \frac{B 7}{B 4}+C_{2} \frac{B 6}{B 3}
$$

where $C$ is the SSC; $B 3, B 4, B 6$, and $B 7$ are the GOCI reflectances in bands $3,4,6$, and 7 , respectively; and $C_{0}=0.08823, C_{1}=1.627$, and $C_{2}=1.121$ are empirical parameters. The band centers/widths for bands $3,4,6$, and 7 are 490/20, 555/20,680/10, and $745 / 20 \mathrm{~nm}$, respectively. This algorithm was established using a vast number of field measurements in the YS, with good 

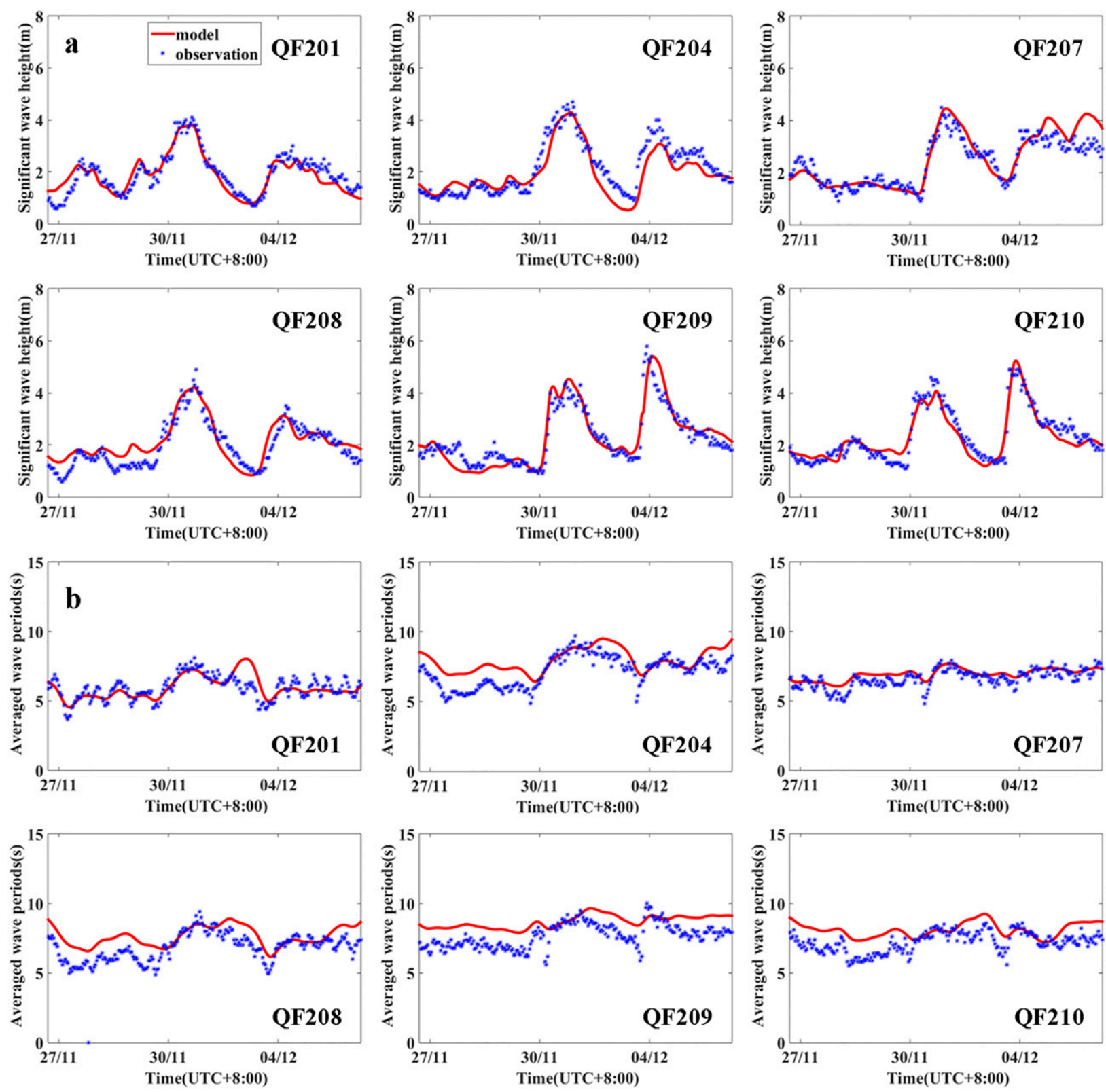

FIG. 6. As in Fig. 5, but for 27 Nov to 6 Dec 2014.

performances (the coefficient of determination $R^{2}=$ 0.94), and should therefore give good results in JZB and its neighboring waters, which belong to the YS. To have complete confidence in using this algorithm for JZB, measured SSC values were compared with those derived from the GOCI taken at the same time. The two sets of values agreed very well, with $R^{2}=0.90$ (Gao et al. 2018).

In selecting GOCI images for comparison with model results in this study, there were two criteria: 1 ) the waves in JZB had to be strong, and 2) the cloud cover in JZB had to be sufficiently low that many continuous images could be taken in the one day. The seven GOCI images taken at hourly intervals on 13 October 2014 and chosen to compare with our model results are shown in Fig. 8a.

The GOCI data showed that SSC was high in the shallow-water areas, with a maximum value of $80 \mathrm{mg} \mathrm{L}^{-1}$, and less than $20 \mathrm{mg} \mathrm{L}^{-1}$ in the middle and entrance of JZB. The SSC was generally lower outside JZB, as shown by both the GOCI data (Fig. 8a) and model results from simulation 8 (Fig. 8d), except in the image at 0730 
TABLE 3. Regression analysis and RMSE of waves between the model and observation.

\begin{tabular}{clccccc}
\hline \hline \multirow{2}{*}{ Period } & & \multicolumn{2}{c}{$\begin{array}{c}\text { Significant } \\
\text { wave heights }\end{array}$} & & \multicolumn{2}{c}{$\begin{array}{c}\text { Averaged } \\
\text { wave periods }\end{array}$} \\
& Station & $R^{2}$ & RMSE & & $R^{2}$ & RMSE \\
\hline 14 Sep-1 Oct 2014 & QF204 & 0.88 & 0.22 & & 0.90 & 1.04 \\
& QF206 & 0.93 & 0.31 & & 0.92 & 0.68 \\
& QF207 & 0.92 & 0.78 & & 0.83 & 0.75 \\
& QF208 & 0.76 & 0.32 & & 0.77 & 0.91 \\
& QF209 & 0.82 & 0.33 & & 0.76 & 1.05 \\
& QF210 & 0.74 & 0.36 & & 0.79 & 0.86 \\
& QF201 & 0.92 & 0.22 & & 0.96 & 0.52 \\
& QF204 & 0.79 & 0.29 & & 0.93 & 0.78 \\
& QF207 & 0.88 & 0.26 & & 0.92 & 0.85 \\
1-31 Dec 2014 & QF208 & 0.92 & 0.27 & & 0.83 & 0.43 \\
7 Nov-13 Dec 2014 Dec 2014 & QF209 & 0.96 & 0.28 & & 0.79 & 1.3 \\
& QF210 & 0.92 & 0.22 & & 0.81 & 0.77 \\
& DJK & 0.92 & 0.09 & & 0.90 & 0.74 \\
& XMD & 0.88 & 0.08 & & 0.83 & 0.92 \\
\hline
\end{tabular}

UTC from the GOCI, in which high SSC appeared outside JZB (Fig. 8a).

As seen in Fig. 8b, the maximum SSC in simulation 1 (current only) was only around $40 \mathrm{mg} \mathrm{L}^{-1}$, which means that the effects of waves on the SSC were significant during the strong wave event in JZB. With the combined wave-current bottom stress included in simulation 2 (Fig. 8c), the maximum SSC increased to $80 \mathrm{mg} \mathrm{L}^{-1}$, but the areas of high SSC were still restricted. When all wave-current interaction mechanisms were included, in simulation 8 , the horizontal distribution of SSC became much more comparable to that derived from the GOCI.
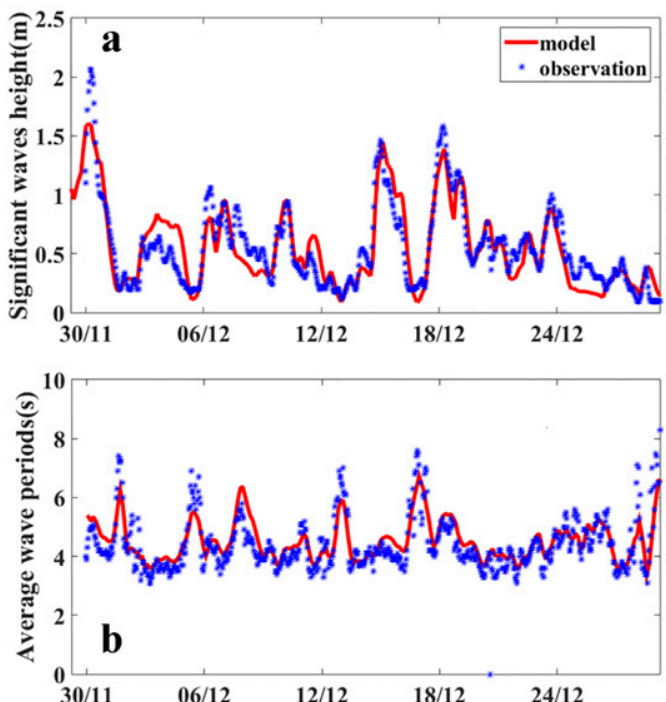

FIG. 7. Comparison of observed and modeled significant wave heights and averaged wave periods at stations (a),(b) DJK and (c),(d) XMD
To quantify the differences between the GOCI data and the model simulations better, three estimators were employed: $R^{2}$, the RMSE, and the skill score (SS) (Murphy 1988). The SS is given by

$$
\mathrm{SS}=1-\frac{\sum\left(X_{m}-X_{o}\right)^{2}}{\sum\left(X_{o}-\overline{X_{o}}\right)^{2}},
$$

where $X_{m}$ and $X_{o}$ are the variables from the model and observation, respectively, and the overbar represents a time average. According to Allen et al. (2007), an SS $>$ 0.65 is classified as excellent, $0.5<\mathrm{SS}<0.65$ as very good, $0.2<\mathrm{SS}<0.5$ as good, and $\mathrm{SS}<0.2$ as poor.

With these estimators, the results of the three simulations are now compared with the GOCI data: the currentonly simulation (simulation 1; Fig. 8b); the simulation with combined wave-current bottom stress only (simulation 2; Fig. 8c), as used in most other studies; and the simulation with all wave-current interaction mechanisms included (simulation 8; Fig. 8d). If simulation 8 is significantly more accurate than simulation 2 , this will show that more wavecurrent interaction mechanisms than just the combined wave-current bottom stress should be included in the model.

Unsurprisingly, simulation 1 performed worst, with $R^{2}=$ $0.15, \mathrm{RMSE}=18.7 \mathrm{mg} \mathrm{L}^{-1}$, and $\mathrm{SS}=0.17$ all indicating poor accuracy. With the combined wave-current bottom stress included in simulation 2, all the estimators improved compared with simulation 1 (Fig. 9b), with the SS of 0.31 a "good" classification. However, when all the wavecurrent interaction mechanisms were included in simulation 8 , the model performance was significantly better than
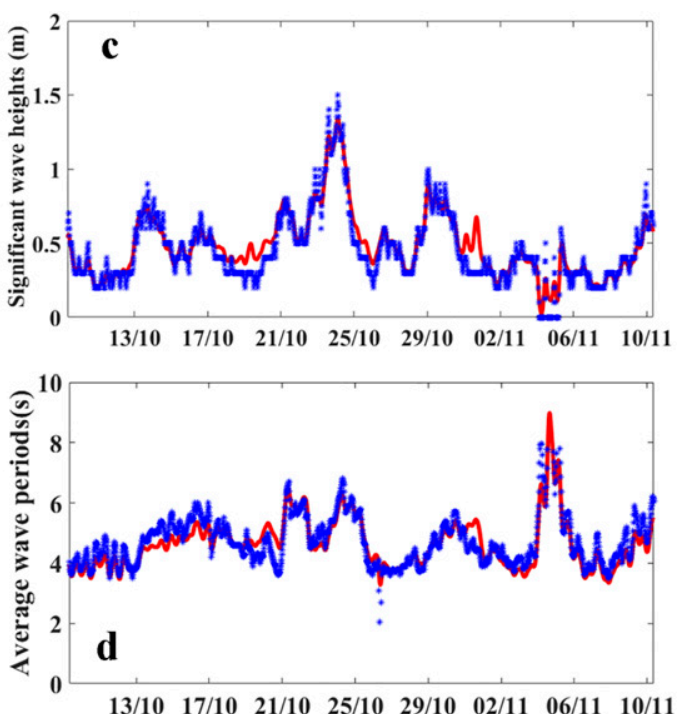
TABLE 4. Summary of the mathematical expressions for the wave-current interaction mechanisms.

\begin{tabular}{|c|c|}
\hline Term & Mathematical expression \\
\hline Combined wave-current bottom stress & $\boldsymbol{\tau}_{w c}=\boldsymbol{\tau}_{c}+\boldsymbol{\tau}_{w m}[$ Eq. (15)] \\
\hline Wave dissipation & $\begin{array}{l}\frac{\partial q^{2}}{\partial z}=\frac{2 \alpha_{C B} u_{\tau s}^{3}}{K_{q}} ; l=\max \left(\kappa z_{w}, l z\right) \text { at } z=s(x, y, t)[\text { Eq. (A14a) }] \\
\frac{\partial q^{2}}{\partial z}=\int_{-\pi}^{-\pi} S_{\theta \mathrm{Bdis}} d \theta ; l=0 \text { at } z=-H(x, y)[\text { Eq. (A14b)] }\end{array}$ \\
\hline Form drag & $\left(\tau_{p x}, \tau_{p y}\right)=\frac{\cosh [2 k D(1+\varsigma)]}{2 \pi \sinh (2 k D)} \int_{0}^{2 \pi} P_{w 0} \sin \phi \frac{\partial \eta}{\partial x_{\alpha}} d \theta[$ Eq. (A9)] \\
\hline Wave radiation stress & 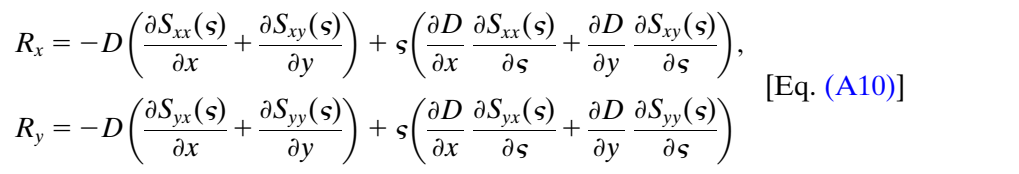 \\
\hline $\begin{array}{l}\text { Mean current advection and refraction } \\
\text { of wave energy }\end{array}$ & $\begin{array}{l}\frac{\partial E_{\theta}}{\partial t}+\frac{\partial}{\partial x_{\alpha}}\left[\left(\bar{c}_{g \alpha}+\bar{u}_{A \alpha}\right) E_{\theta}\right]+\frac{\partial}{\partial \theta}\left(\bar{c}_{\theta} E_{\theta}\right)+\bar{S}_{\alpha \beta} \frac{\partial U_{\alpha}}{\partial x_{\beta}} D d s=S_{\theta \text { in }}-S_{\theta \text { Sdis }}-S_{\theta \text { Bdis }} \text { [Eq. (A1)] } \\
\text { The current advection and refraction of wave energy are the second and third } \\
\text { terms, respectively, on the left-hand side. }\end{array}$ \\
\hline
\end{tabular}

simulation 2 (Fig. 9c): the RMSE was reduced by $30 \%$, $R^{2}$ increased from 0.43 to 0.72 , and the SS of 0.51 was a "very good" classification. Both the qualitative and quantitative comparisons between the GOCI data and model simulations demonstrate that using only the combined wave-current bottom stress, as in most previous studies (e.g., Tang and Grimshaw 1996; Lou et al. 2000; Wang et al. 2000; Wang et al. 2007), is not sufficient to model accurately the effects of waves on the suspended-sediment dynamics.

Based on this finding, the next step is to use the coupled wave-current-sediment model to investigate the effects of the six wave-current interaction mechanisms separately, to gain a further understanding of the relative contribution and role of each mechanism. As well as investigating the effects of the individual wave-current interactions on the horizontal distribution of SSC, we use station A (Fig. 1) as a representative location at which to examine thoroughly how each of the wave-current interaction mechanisms affects the vertical current velocities, vertical eddy viscosities, and bottom stress, and consequently the SSC. Station A is located in an area that experiences significant effects from the wave-current interactions. The horizontal distribution of SSC in that area from simulation 8 (all wave-current interaction mechanisms included) agreed well with that from the GOCI (Figs. 8a,d). Therefore, station $\mathrm{A}$ is a good location at which to investigate how the wave-current interaction terms affect the SSC. The water depth at station $\mathrm{A}$ is around $4.9 \mathrm{~m}$; water elevations, significant wave heights, and peak wave periods during the period from 0130 to 0730 UTC 13 October 2014 are given in Fig. 10. This time period is the same as that during which the model results were validated against the GOCI data (Fig. 8), so the discussion of the results at station A focuses on this time period.

\section{b. Combined wave-current bottom stress included (simulation 2)}

As JZB is connected to the YS through a narrow tidal inlet that can restrict the propagation of waves, the significant wave heights inside JZB are slightly lower than outside, as can be seen in the snapshot of significant wave heights in Fig. 2a. The snapshot of wave orbital velocities near the bottom (Fig. 2b) shows a quite different distribution pattern, with high values around $0.2 \mathrm{~m} \mathrm{~s}^{-1}$ concentrated in the very shallow water areas (depth less than around $2 \mathrm{~m}$ ) near

TABLE 5. Summary of the configurations in the model simulations.

\begin{tabular}{cl}
\hline \hline Simulation & \multicolumn{1}{c}{ Description } \\
\hline 1 & Current only \\
2 & $\begin{array}{c}\text { Simulation 1 plus combined wave-current } \\
\text { bottom stress } \\
\end{array}$ \\
3 & Simulation 1 plus wave dissipation \\
4 & Simulation 1 plus form drag \\
5 & Simulation 1 plus wave radiation stress \\
6 & Simulation 1 with all wave-current interaction \\
& mechanisms except mean current advection \\
& of wave energy \\
7 & Simulation 1 with all wave-current interaction \\
& mechanisms except mean current refraction \\
& of wave energy \\
8 & Simulation 1 with all wave-current interaction \\
& mechanisms \\
\hline
\end{tabular}




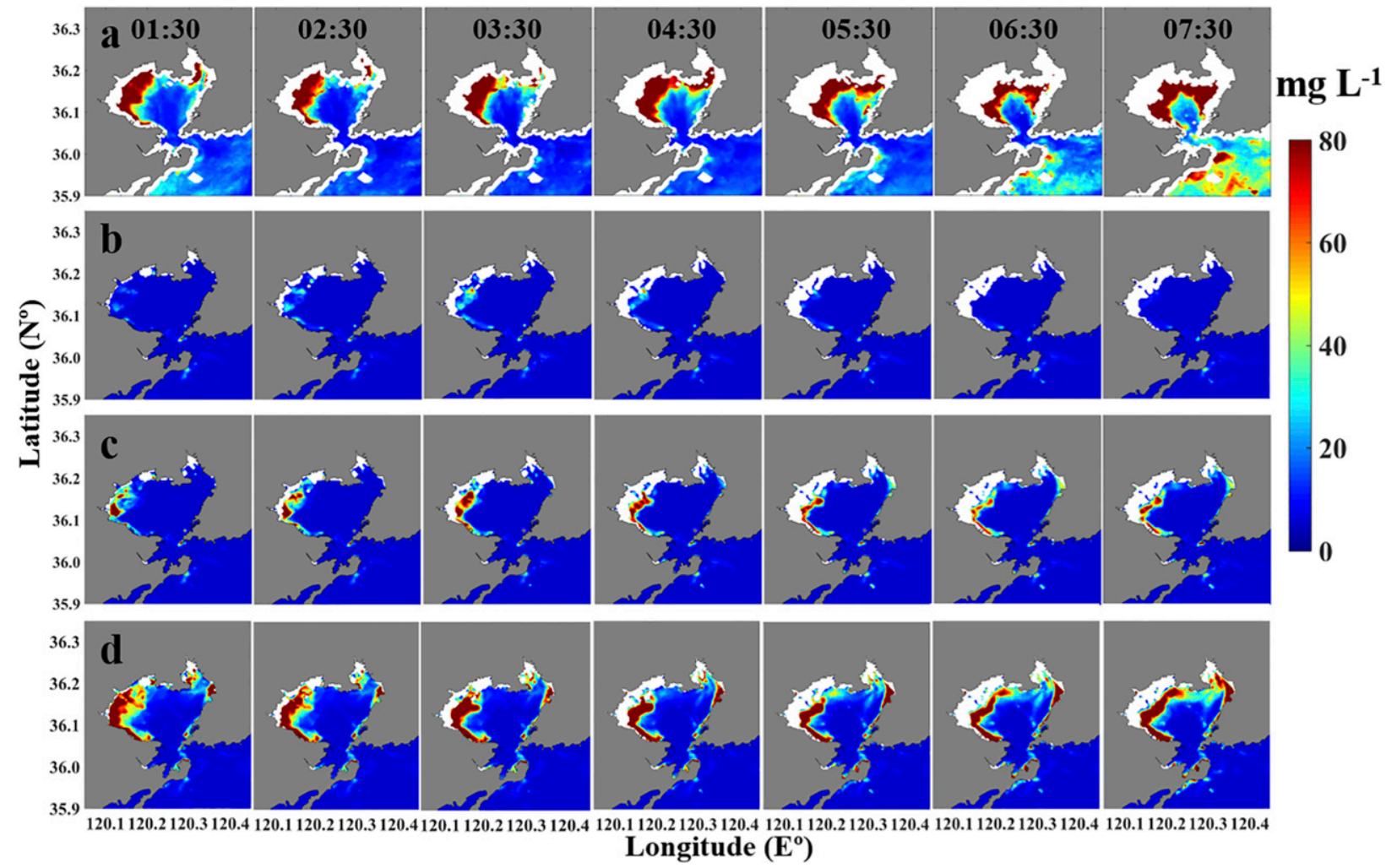

FIG. 8. Surface SSC from 0130 to 0730 UTC 13 Oct 2014 derived from (a) GOCI, (b) simulation 1, (c) simulation 2, and (d) simulation 8. The white areas indicate the tidal flats emerging at the time.

the bay shore because the bottom wave orbital velocities are inversely proportional to water depth.

The combined wave-current bottom stress is the maximum instantaneous shear stress, which is the vector sum of the time-averaged instantaneous shear stress of the current and the maximum shear stress induced by the waves [section $6 b(3)$ ]. As can be seen in Eq. (18), the maximum shear stress induced by the waves is proportional to the square of the bottom wave orbital velocity. Hence, the bottom wave orbital velocities influence the combined wave-current bottom stress.

Figure 11a shows the differences in the monthly and depth-averaged SSC between simulation 2 and simulation 1 . The inclusion of the combined wave-current bottom stress in simulation 2 had a large effect on the SSC, especially in the shallow-water areas near the shore of JZB, with an average increase there of around $20 \mathrm{mg} \mathrm{L}^{-1}$. Figure $11 \mathrm{~g}$ shows the difference in the monthly averaged bottom stress between simulation 2 and simulation 1; this has the same distribution pattern as the difference in the SSC in Fig. 11a. Therefore, on a monthly time scale, the combined wave-current bottom stress (tidally and depth averaged) affects the SSC through its effect on the process of resuspension.
Next we examine the vertical changes on an intratidal time scale. Figure 12 plots the differences between simulation 2 and simulation 1 for the bottom stress, wave orbital velocity near the bottom, SSC, and current velocity at station A from 0130 to 0730 UTC 13 October 2014 (UTC); these plots show the effect of including the combined wave-current bottom stress in the simulation. Figure 12a shows that the bottom stress has increased in simulation 2 compared to simulation 1 and that the increase has a similar pattern to the increase in bottom wave orbital velocity. As a result of the enhanced resuspension, the SSC near the bottom has also increased significantly; the difference reached a peak value (around $70 \mathrm{mg} \mathrm{L}^{-1}$ ) between hours 5 and 6 (Fig. 12), similar to the difference in bottom stress. The magnitude of the increase in SSC generally decreased from the bottom (sigma coordinate $s=-1)$ to the surface $(s=0)$, and the time variation in the increased SSC showed similar trends from the bottom to the surface. Both the tidally averaged and intratidal results imply that the combined wave-current bottom stress can significantly affect sediment resuspension, and consequently the SSC. 

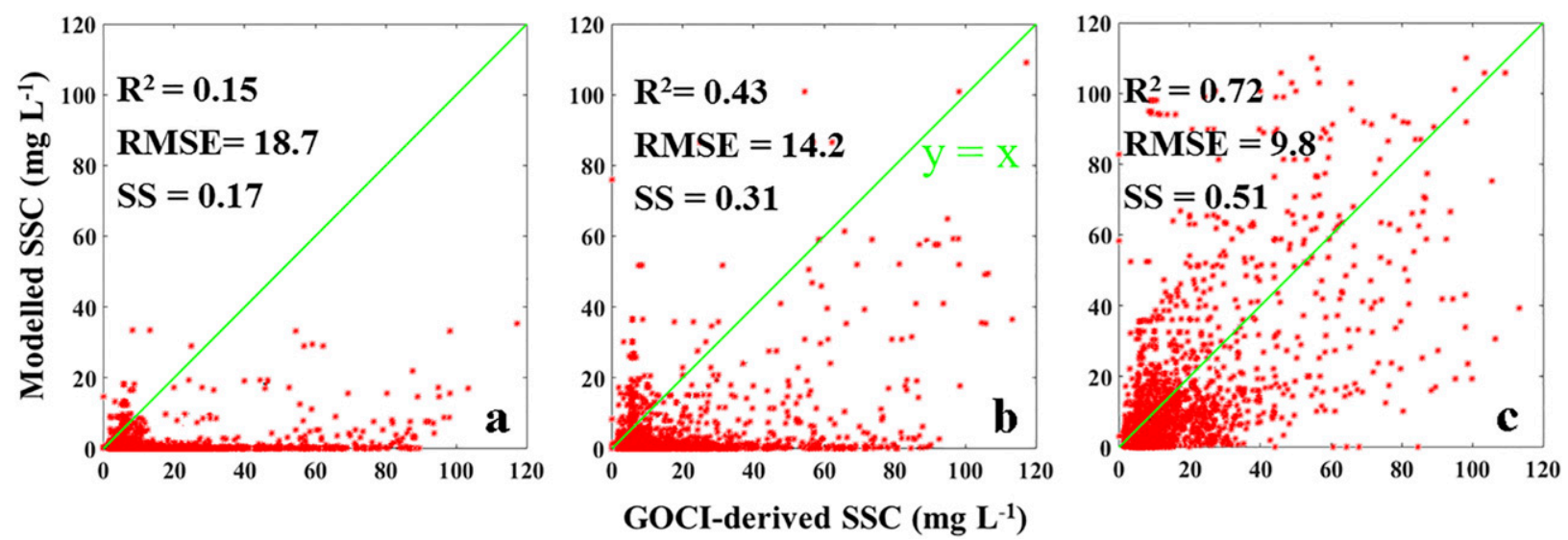

FIG. 9. Scatterplots of the GOCI-derived SSC and the modeled SSC in (a) simulation 1, (b) simulation 2, and (c) simulation 8 , respectively. The green lines show where the simulation results are equal to the GOCI-derived results. The corresponding statistic estimators are also given in each panel.

\section{c. Wave dissipation included (simulation 3)}

Wave dissipations at the surface and the bottom enter into the vertical turbulent energy equation as the diffusional boundary condition [Eqs. (14a) and (14b)]. Wave dissipation is a sink in the wave energy equation but a source in the vertical turbulent energy equation. In consequence, wave dissipation is expected to enhance vertical mixing.

In simulation 3 (wave dissipation included), the vertical mixing was significantly enhanced compared with simulation 1 in the surface layers $(-0.1<s<0)$, as seen in Fig. 13, which plots the time-area-averaged result for JZB. It can also be seen from Fig. 13 that the bottom dissipation had only a minor effect on the vertical mixing.

The enhanced vertical mixing could affect not only the vertical exchange of suspended sediments but also the currents, and consequently the advection and resuspension of suspended sediments. However, compared with the combined wave-current bottom stress, wave dissipation caused only small changes to the SSC, in both the tidally averaged (Fig. 11b) and intratidal results (Fig. 14). Hence, wave dissipation had little effect on the current velocities (meaning the magnitudes of current in this study) and SSC, except in the thin top layer shown in Fig. 14c.

\section{d. Form drag included (simulation 4)}

The horizontal (kinematic) surface wind stress can be divided into a turbulent viscous part (skin friction) and a pressure part (form drag) (Mellor et al. 2008). The pressure part of the wind stress is associated with the horizontal gradient in wave pressure as a result of water elevation induced by the waves [Eq. (9)]. The wind pressure can be projected into the subsurface of the water column as form drag and competes with the turbulence-supported stress in the momentum equations [Eqs. (7) and (8)] and the vertical turbulent closure equations [Eqs. (12) and (13)] (Mellor 2005). Form drag
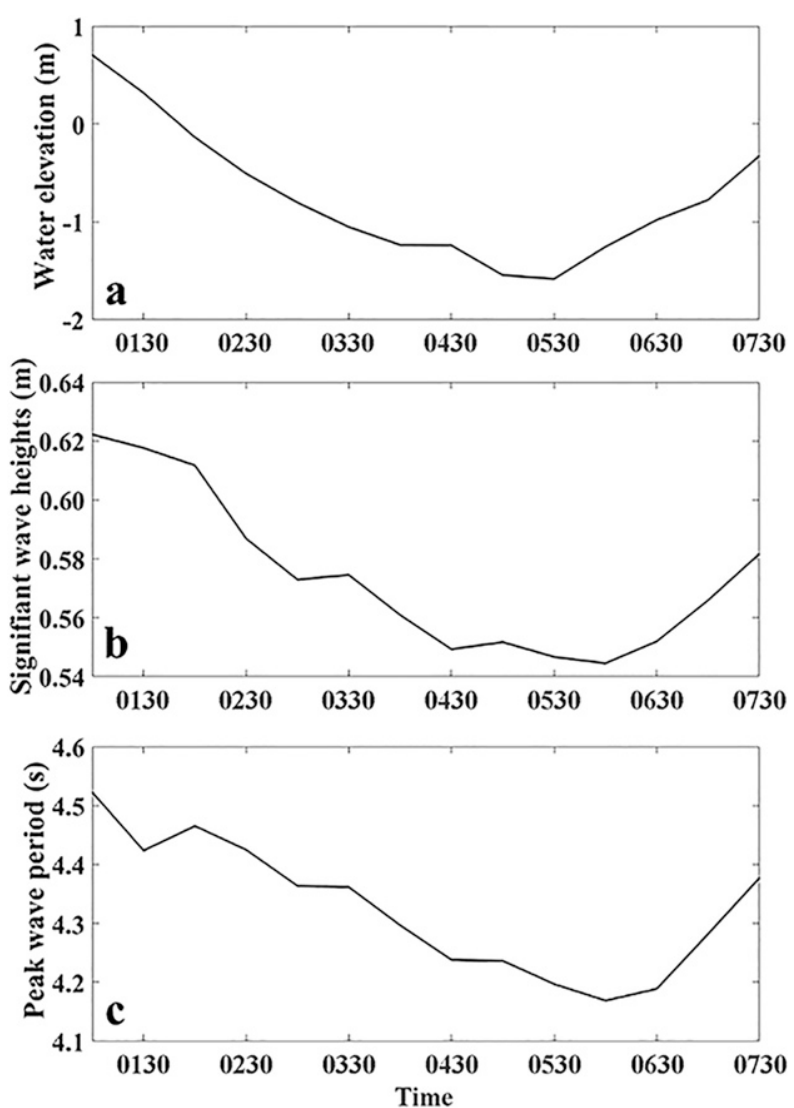

FIG. 10. (a) Water elevation, (b) significant wave height, and (c) peak wave period at station A from 0130 to 0730 UTC 13 Oct 2014. 

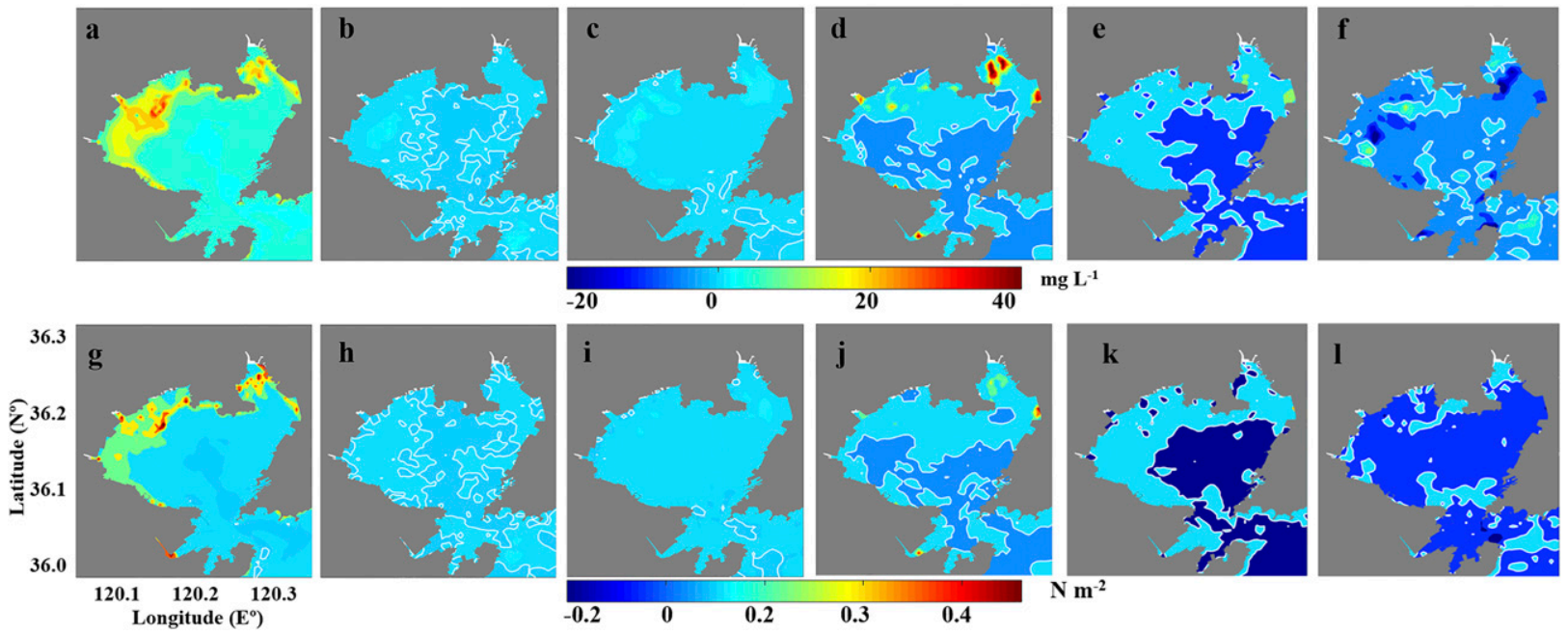

FIG. 11. Differences in the monthly and depth-averaged SSC for simulations (a) $2-1$, (b) $3-1$, (c) $4-1$, (d) 5 - 1, (e) 8 - 6, and (f) $8-7$. Differences in the monthly averaged bottom stress for simulations (g) $2-1$, (h) $3-1$, (i) $4-1$, (j) $5-1$, (k) $8-6$, and (l) $8-7$. White lines denote $0 \mathrm{mg} \mathrm{L}^{-1}$ or $0 \mathrm{~N} \mathrm{~m}^{-2}$.

can affect the vertical mixing in each sigma layer, with the maximum increase of around $30 \%$ in the middle layers $(s \approx-0.4)$ as shown by the time-area-averaged result for JZB (Fig. 13).

Similar to the wave dissipation, the differences in the tidally averaged SSC and bottom stress caused by form drag were not large (Fig. 11c). The tidally averaged SSC clearly experienced a larger increase in the shallowwater areas near the head of JZB than in the neighboring deeper-water areas, which did not match the difference in the tidally averaged bottom stress (Fig. 11i). Therefore, this discrepancy must be the result of the enhanced vertical mixing there, as stronger vertical mixing caused by form drag (Fig. 13) would maintain a higher SSC in the water column, similar to the larger increase in SSC in the northwest of JZB as a result of wave dissipation.

On an intratidal time scale, the influence of form drag cannot be ignored (Fig. 15). As shown in Fig. 15b, the maximum difference in the SSC as a result of form drag exceeded $14 \mathrm{mg} \mathrm{L}^{-1}$. The magnitude of the form drag deceased with depth (Fig. 15e) and significantly enhanced the vertical mixing in the upper layers of the water column (Fig. 15c). Form drag changed the current velocities by around $0.05 \mathrm{~m} \mathrm{~s}^{-1}$ in the upper layer but had a much smaller effect on the current velocities near the bottom; hence the difference in the bottom stress caused by form drag was not large. As a result of the enhanced vertical mixing in the upper layers and the relatively smaller differences in the bottom stress, the difference in the SSC caused by the form drag was larger in the upper layers $(s>-0.7)$ than in the lower layers $(s<-0.7)$ (Fig. 15b). In the upper layers, the change in the pattern of current velocities caused by form drag showed no clear correlation with that in the SSC, so that the difference in the SSC in the upper layer must have been caused by the enhanced vertical mixing. The increase in the SSC in the whole water column gradually decreased with time, along with a reduction in the increase in bottom stress. Hence, the effect of form drag on bottom stress
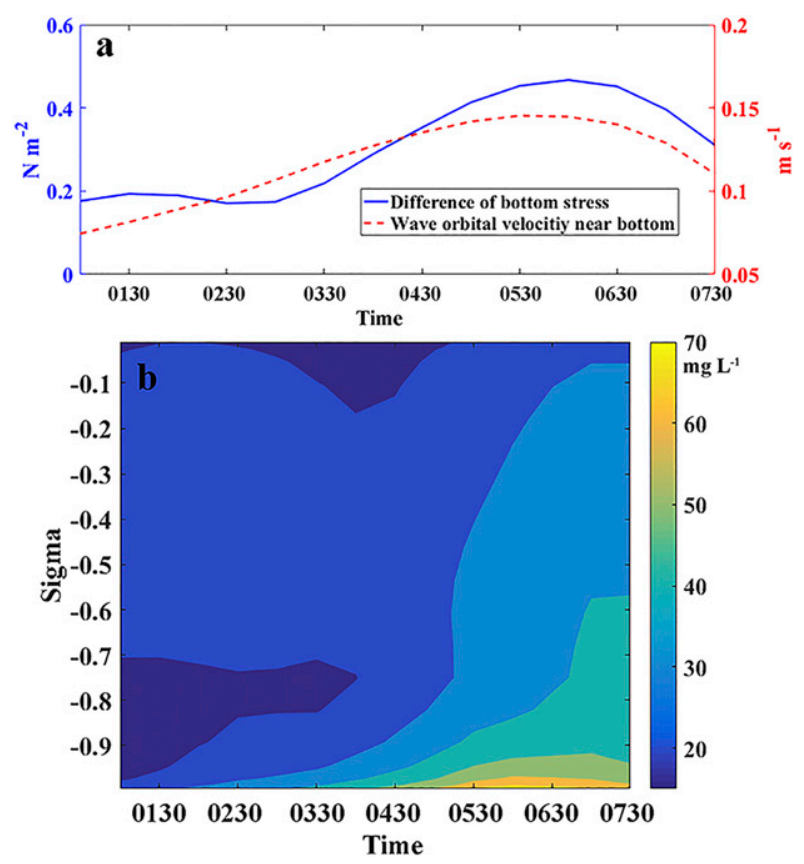

FIG. 12. Differences in (a) the bottom stress, the wave orbital velocity near the bottom, and (b) the SSC, simulation 2 minus simulation 1, at station A from 0130 to 0730 UTC 13 Oct 2014. 


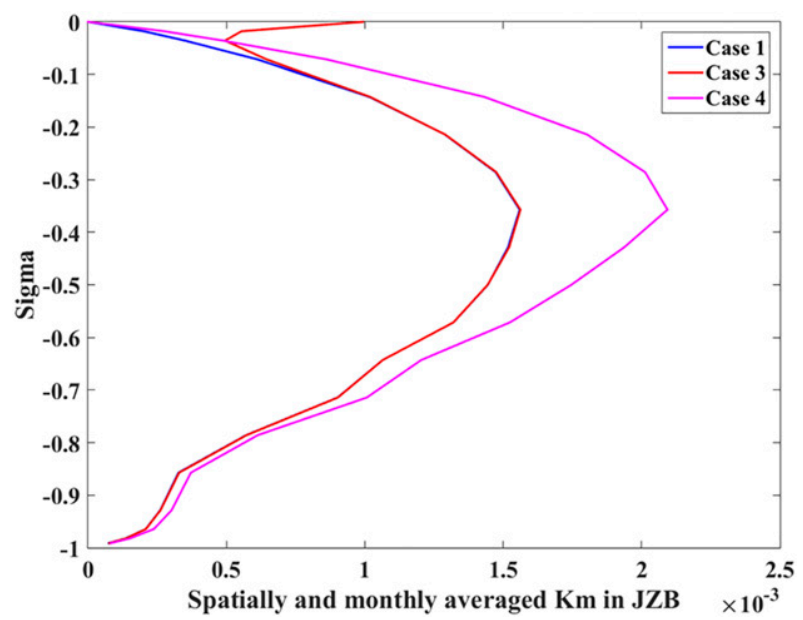

FIG. 13. Spatially and monthly averaged vertical eddy viscosities of simulations 1,3 , and 4 .

determined the differences in the SSC in the whole column, and its effect on vertical mixing determined the vertical distribution of the SSC differences.

\section{e. Wave radiation stress included (simulation 5)}

Wave radiation stress can be regarded as the waveaveraged effects on the current, modeled as the divergence of a stress tensor (Lane et al. 2007). As pointed out by Longuet-Higgins and Stewart (1964), wave radiation stress plays an important role in a variety of oceanographic phenomena, for example, in the change in mean sea level due to storm waves (wave setup), the generation of surf beats, the interaction of waves with steady currents, and the steepening of short gravity waves on the crests of longer waves. The dynamics in the surf zone (e.g., Conley and Inman 1992; Conley and Beach 2003) is not yet included in the MDO-Wave model. Therefore, this study focuses on the effect of the wave-current interactions (Mellor 2003; Mellor et al. 2008; Mellor 2015) in the shallow-water areas; wave setup and surf beat are not considered here.

Pivotal to this study is that the wave-induced currents are essential to sediment transport (Sheng and Liu 2011). The differences in the tidally and vertically averaged SSC caused by wave radiation stress exhibit strong spatial variation in JZB: wave radiation stress mostly reduced the SSC in the south part of JZB and increased the SSC in the north part, with maximum increase in the northeast corner (Fig. 11d). This distribution pattern of the differences in SSC is similar to that of the difference in bottom stress (Figs. 10d,j).

As shown in Fig. 16, wave radiation stress altered the current velocities significantly in the middle layers of the water column at station $\mathrm{A}$, with the maximum variation there. The largest changes in SSC (around $10 \mathrm{mg} \mathrm{L}^{-1}$ ) were also found in the middle layers, which means changed currents affected the horizontal transport of suspended sediments. Wave radiation stress also affected current velocities near the bottom, leading to variations in bottom stress, with a maximum increase of $0.03 \mathrm{~N} \mathrm{~m}^{-2}$. The changed bottom stress caused by wave radiation stress affected the SSC near the bottom $(s<-0.75)$.

As pointed out by Ardhuin et al. 2017, the threedimensional wave radiation stress proposed by Mellor (2003, 2015) missed the divergence of vertical flux associated with nonhydrostatic pressure perturbations. However, this problem cannot be solved until the analytical solution to the wave motion to second order $\left(\varepsilon_{2}\right)$ is found, which has not been completed in any other theories yet (Ardhuin et al. 2017). In this study, the influences of the three-dimensional wave radiation stress on the currents are on the order of $0.1 \mathrm{~m} \mathrm{~s}^{-1}$. According to Sheng and Liu (2011), the relative RMS errors of currents induced by three-dimensional radiation stress are $26.2 \%$ when compared to laboratory experiments. The absolute errors of currents induced
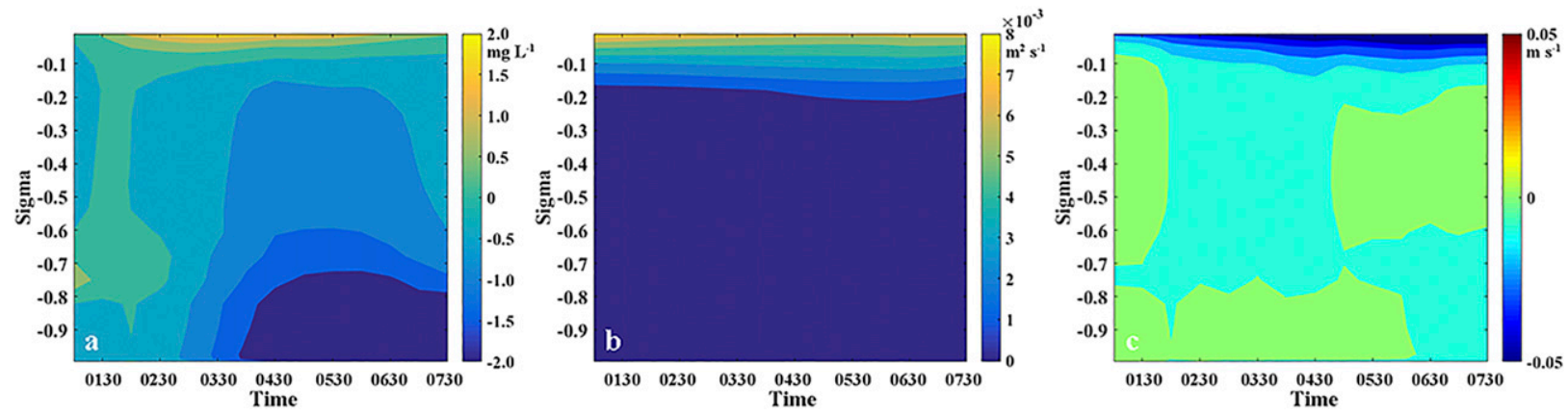

FIG. 14. Differences in (a) the SSC, (b) the vertical eddy viscosities, and (c) the current velocities between simulation 3 and simulation 1 at station A from 0130 to 0730 UTC 13 Oct 2014. 

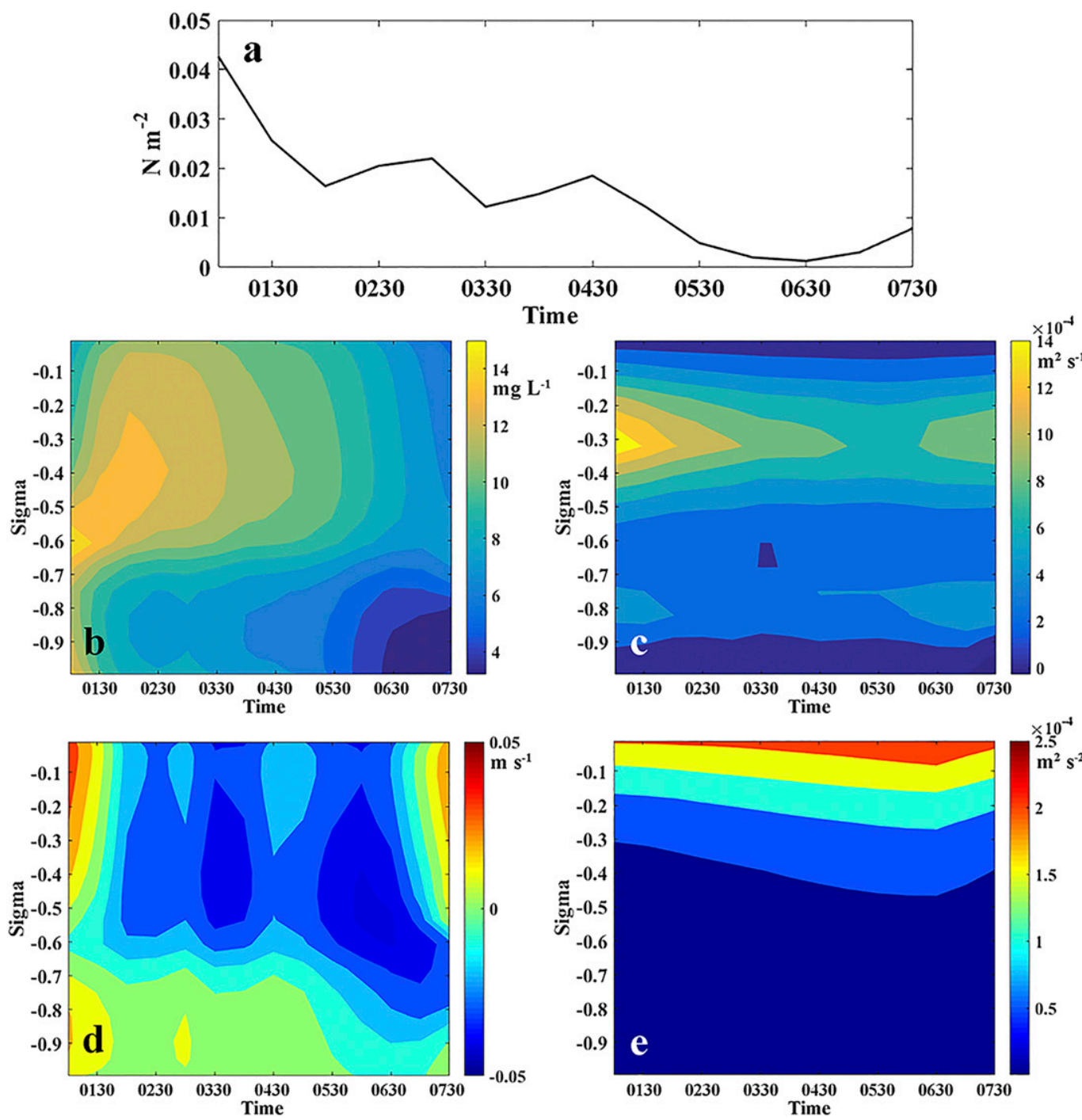

FIG. 15. Differences in (a) the bottom stress, (b) the SSC, (c) the vertical eddy viscosities, (d) the current velocities, and (e) the magnitudes of form drag between simulation 4 and simulation 1 at station A from 0130 to 0730 UTC 13 Oct 2014.

by wave radiation stress in this study are roughly estimated to be on the order of $0.03 \mathrm{~m} \mathrm{~s}^{-1}$, which would secondarily affect the suspended-sediment dynamics. More noticeable errors are expected when modeling suspended-sediment dynamics during typhoon or hurricane events when the waves are much stronger than that in this study.

\section{f. Mean current advection and refraction of wave energy included (simulations 6 and 7)}

Currents can affect the propagation of wave energy in the advection and refraction terms of Eq. (1), called mean current advection and refraction of wave energy, respectively. The effects of these two mechanisms are feedback from the waves to the currents, and consequently the SSC. The effects of the waves on the currents are changed if the corresponding terms are omitted from the wave model. Separate model results for each mechanism are given, but both are included in this section as the mechanisms are similar.

In simulation 6, we included in the model of simulation 1 all the wave-current interaction mechanisms except the mean current advection of wave energy [the second term on the left-hand side of Eq. (1)]. Similarly, in simulation 7, we included all the wave-current interaction mechanisms except the mean current refraction of wave energy [the third term on the left-hand side of Eq. (1)]. Finally, in simulation 8 , we included all the wave-current interaction mechanisms. The differences between simulation 8 and 


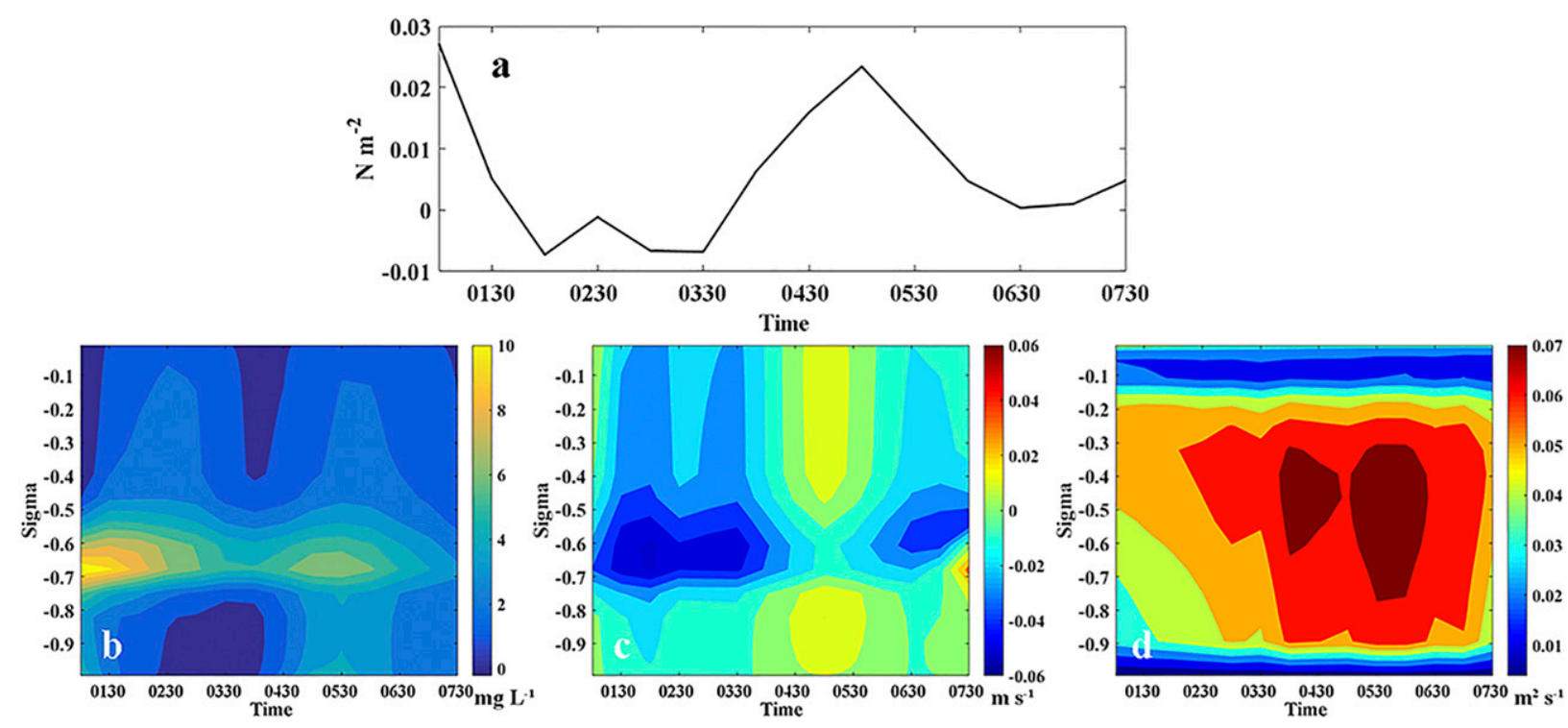

FIG. 16. Differences in (a) the bottom stress, (b) the SSC, (c) the current velocities, and (d) the magnitudes of wave radiation stress between simulation 5 and simulation 1 at station A from 0130 to 0730 UTC 13 Oct 2014.

simulation 6 , and between simulation 8 and simulation 7 , were caused by mean current advection and by refraction of wave energy, respectively.

The tidally and vertically averaged result in Fig. 11e shows that the mean current advection of wave energy generally increased SSC in the northern part and along the west coast of JZB and reduced SSC in the middle part and along the east coast. This pattern is similar to the difference in the tidally averaged bottom stress caused by the mean current advection of wave energy (Fig. 11k). The intratidal results at station A show that including the mean current advection of wave energy clearly changed the significant wave heights and that the magnitudes of the differences were generally in proportion to the vertically averaged current velocities. As the wave heights changed, the effects of the other wavecurrent interaction mechanisms also changed. The resulting changes were nonlinearly superposed, leading to significant variations in the current velocities and vertical mixing in the whole water column (Figs. 17d,e). The difference in bottom stress was dominated by the difference in current velocities near the bottom; even though the bottom wave orbital velocities were increasing most of the time, the bottom stress was significantly reduced in the first three hours but increased subsequently, the same as the variation in the bottom current velocities (Figs. 17b,d). The differences in the SSC in the lower half of the water column showed a similar changing pattern to the differences in bottom stress. The maximum magnitude of the SSC difference caused by the mean current advection of wave energy was around $30 \mathrm{mg} \mathrm{L}^{-1}$, larger than the individual differences from wave dissipation, form drag, and wave radiation stress.

As with the mean current advection of wave energy, the inclusion of mean current refraction of wave energy (simulation 8 vs simulation 7) clearly changed the significant wave heights at station A (Fig. 18a). The mean current refraction of wave energy also caused significant changes in the current velocities and vertical mixing. The current velocities were reduced near the bottom at all times, whereas the significant wave heights were increased except during the third hour. As a result, the bottom stress was reduced during the first four hours and enhanced subsequently, leading to similar changes in the SSC. The maximum increase/decrease in the SSC caused by the mean refraction of wave energy was 30 and $40 \mathrm{mg} \mathrm{L}^{-1}$, respectively, comparable to that caused by the combined wave-current bottom stress.

\section{Summary and conclusions}

In this study, a three-dimensional coupled wavecurrent-sediment model was set up to investigate the effect of wave-current interaction mechanisms on the suspended-sediment dynamics in Jiaozhou Bay (JZB), a tidally dominated bay. The wave model used was developed by Mellor et al. (2008). Compared with community wave models such as SWAN and WAVEWATCH III, it runs faster, with reliable results, when coupled with the hydrodynamics model FVCOM. 


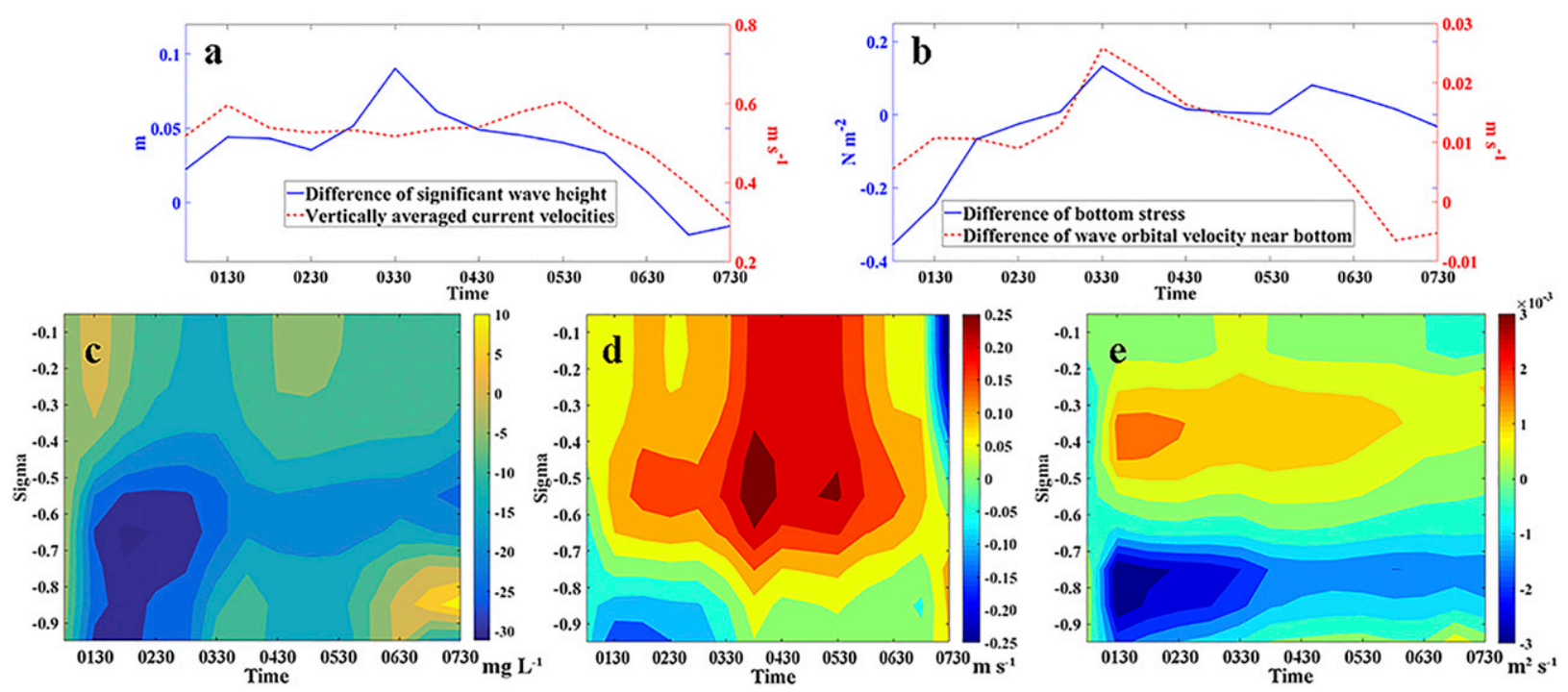

FIG. 17. (a) Vertically averaged current velocities and differences in the significant wave heights between simulation 8 and simulation 6 at station A from 0130 to 0730 UTC 13 Oct 2014. Differences in (b) the bottom stress and wave orbital velocity near bottom, (c) the SSC, (d) the current velocities, and (e) the vertical eddy viscosities between simulation 8 and simulation 6 at station A from 0130 to 0730 UTC 13 Oct 2014.

Most importantly, all the wave-current interaction mechanisms proposed by Mellor (2003), Mellor et al. (2008), and Mellor (2015) have been taken into consideration. Comparison between model results and GOCI data shows that the simulation with all the wave-current interaction mechanisms included performed much better than the simulation with only the combined wavecurrent bottom stress, the case in most other studies.

Numerical simulations with the respective wavecurrent interaction mechanisms included one at a time were designed to investigate their effects on the suspended-sediment dynamics. The tidally and vertically averaged results indicated that all the wave-current interaction mechanisms affected the suspended-sediment concentration (SSC), primarily through their effects on the bottom stress. These results also showed that the combined wave-current bottom stress did cause much larger differences in the bottom stress and the SSC than the other wave-current interaction mechanisms: it consistently increased the bottom stress whereas the other terms alternately increased and decreased it when waves were significant. However, the contributions of the other wave-current interaction mechanisms, especially the mean current advection and refraction of wave energy, and the wave radiation stress cannot be neglected.

On an intratidal time scale, the other wave-current interaction mechanisms were much more comparable in effect to the combined wave-current bottom stress. Wave dissipation and form drag both affected the vertical mixing first, then the current velocities and the SSC. The effect of wave dissipation was smallest, as it only increased vertical mixing in a very thin top layer. Unlike wave dissipation, form drag enhanced vertical mixing in most parts of the water column. Furthermore, it led to significant changes in the current velocities, and consequently the bottom stress. The changes in SSC caused by form drag were the consequence of its effect on the vertical mixing in the top layer and its effect on the bottom stress in the bottom layer. Wave radiation stress, a stress tensor, directly changed the current velocities and the bottom stress. The changes in SSC caused by the wave radiation stress were the consequence of its effect on the horizontal transport of suspended sediment in the top layer and its effect on the bottom stress in the bottom layer. Mean current advection and refraction of wave energy affected the propagation of waves, thus resulting in changes in the other wave-current interaction mechanisms. The contributions of both the mean current advection and refraction of wave energy were as significant as that of the combined wave-current bottom stress and larger than the rest of the mechanisms, wave radiation stress, form drag, and wave dissipation.

As a conclusion, the suspended-sediment dynamics is governed not only by the bottom resuspension but also by the horizontal advection by currents and vertical mixing, so that considering only the combined wave-current interaction bottom stress in modeling the SSC is clearly far from adequate. Wave 

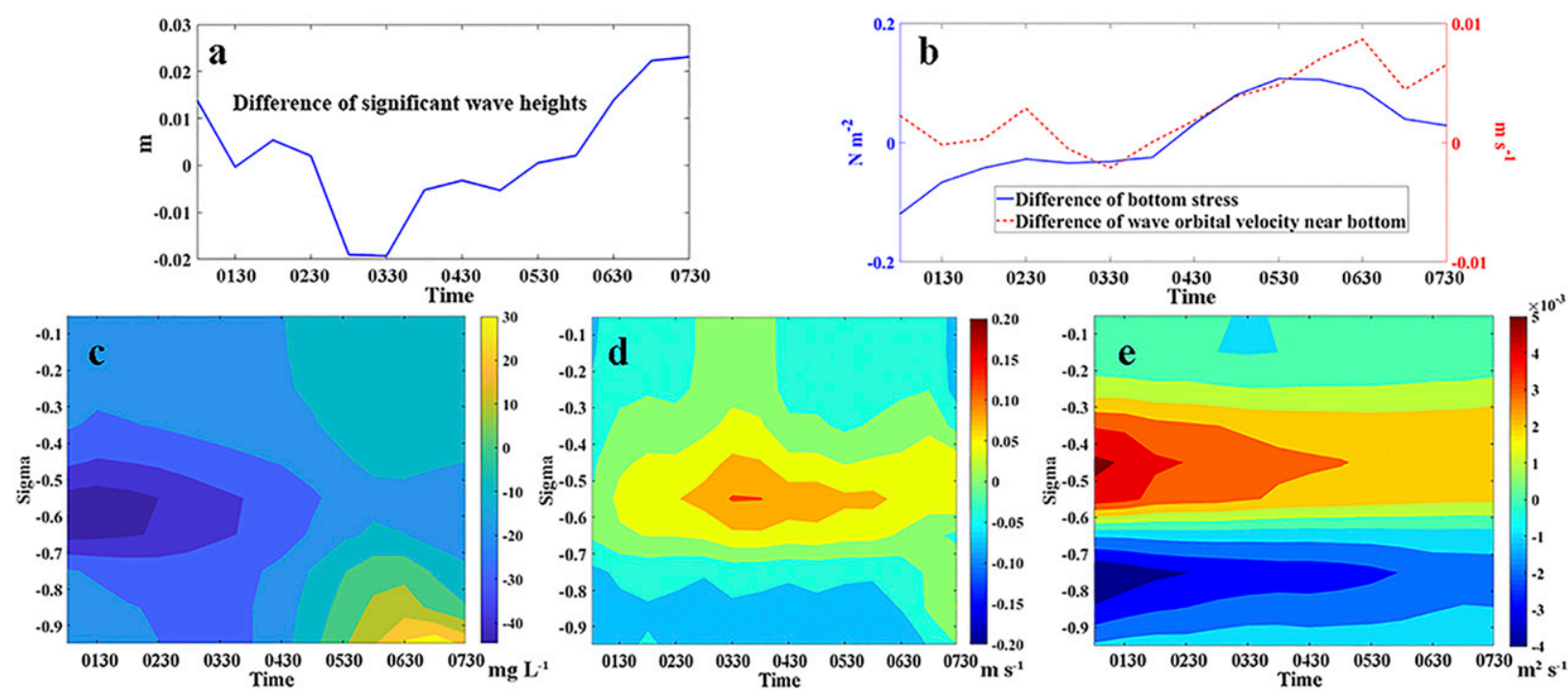

FIG. 18. Differences in (a) the significant wave heights, (b) the bottom stress and the wave orbital velocities near bottom, (c) the SSC, (d) the current velocities, and (e) the vertical eddy viscosities between simulation 8 and simulation 7 at station A from 0130 to 0730 UTC on 13 Oct 2014.

dissipation, form drag, wave radiation stress, and mean current advection and refraction wave energy can significantly affect the horizontal and vertical exchange of suspended sediments and even the bottom stress. Their effects on the modeling of suspended-sediment dynamics during strong wave events deserve more attention in the future.

Acknowledgments. G. Gao was supported by the China Scholarship Council and a UNSW Canberra Top-up Scholarship. This work was also supported by the China Ministry of Science and Technology under Contract 2015CB452905 and the National Natural Science Foundation of China (41406097); by Intersect, the National Computational Infrastructure Facility at the Australian National University; and by a UNSW LIEF Grant Share LE120100181. Dr. Yin and Dr. Yang were supported by the National Natural Science Foundation of China (41576023 and 41476019), the National Key Research Development Program of China (2017YFC1404000 and 2016YFC1401601), the National Key Research and Development Plan Sino-Australian Center for Healthy Coasts (2016YFE0101500), and the Strategic Priority Research Program of the Chinese Academy of Sciences (XDA11020104 and XDA110203052). This is Publication Number 47 of the Sino-Australian Research Centre for Coastal Management. The authors appreciate comments on the manuscript from Dr. Peter McIntyre at UNSW Canberra. The authors are also grateful to the State Oceanic Administration of China, the North China Sea Marine Forecasting Centre of the State Oceanic Administration, and the Qingdao Meteorological Administration for providing the data used in this study.

\section{APPENDIX}

\section{Introduction of the Coupled Wave-Current-Sediment Model}

\section{a. The wave model}

Much of what follows in this section is from the work of Professor George Mellor and coworkers. Their work and codes can be accessed directly (at shoni2.princeton. $\mathrm{edu} / \mathrm{ftp} / \mathrm{glm} /$ ). The symbols used in this section are mostly described in Table 1 with parts of them further explained below.

The spectrally averaged wave energy $E_{\theta}=\int_{0}^{\infty} E_{\sigma, \theta} d \sigma$ is found by solving

$$
\begin{aligned}
& \frac{\partial E_{\theta}}{\partial t}+\frac{\partial}{\partial x_{\alpha}}\left[\left(\bar{c}_{g \alpha}+\bar{u}_{A \alpha}\right) E_{\theta}\right]+\frac{\partial}{\partial \theta}\left(\bar{c}_{\theta} E_{\theta}\right)+\int_{-1}^{0} \bar{S}_{\alpha \beta} \frac{\partial U_{\alpha}}{\partial x_{\beta}} D d s \\
& \quad=S_{\theta \text { in }}-S_{\theta \text { Sdis }}-S_{\theta \text { Bdis }}
\end{aligned}
$$

where there is implied summation in the second term over $\alpha=1,2$ and in the fourth term over $\alpha$ and $\beta$ : $\alpha$, $\beta=1,2$.

The horizontal coordinates here are $x_{\alpha} ; \alpha=1,2$, with $x_{1}=x$ and $x_{2}=y$, and the vertical sigma coordinate is 
$\varsigma=(\hat{\eta}-z) / D$, where $z$ is the vertical coordinate, positive upward, with $z=0$ at mean sea level.

The overbars represent spectral averages; for example, the spectrally averaged group velocity is

$$
\bar{c}_{g \alpha}=\frac{\int_{0}^{\infty} c_{g \alpha} E_{\sigma, \theta} d \sigma}{\int_{0}^{\infty} E_{\sigma, \theta} d \sigma},
$$

where $c_{g \alpha}$ is the $\alpha$ component of the group velocity $\mathbf{c}_{g}$.

The first two terms on the left of Eq. (A1) determine the propagation of wave energy in time and horizontal space; the third term is the refraction term, accounting for the change in direction of wave-energy propagation; $u_{A \alpha}$ are the components of the Doppler velocity $\mathbf{u}_{A}$ and $c_{\theta}$ the refraction speed. The $u_{A \alpha}$ and $c_{\theta}$ are given by the following (Mellor et al. 2008):

$$
\begin{aligned}
u_{A \alpha}= & k D \int_{-1}^{0} U_{\alpha}\left\{\frac{\cosh [2 k D(1+\varsigma)]}{\sinh (2 k D)}\right. \\
& \left.+\frac{\sinh [2 k D(1+\varsigma)]}{\sinh ^{2}(k D)}\right\} d s, \text { and } \\
c_{\theta}= & \frac{g}{2 c \cosh ^{2}(k D)}\left(\frac{\partial D}{\partial x} \sin \theta-\frac{\partial D}{\partial y} \cos \theta\right) \\
& +\frac{k_{\alpha}}{k}\left(\frac{\partial u_{A \alpha}}{\partial x} \sin \theta-\frac{\partial u_{A \alpha}}{\partial y} \cos \theta\right),
\end{aligned}
$$

The last term on the left of Eq. (A1) represents the energy exchange with the mean velocity energy equation. The $S_{\alpha \beta}$ is the wave radiation stress term. The $U_{\alpha}$ is the $\alpha$ component of the current velocity $\mathbf{U}$ plus the $\alpha$ component of the Stokes drift velocity $\mathbf{U}_{S}$, with

$$
U_{S \alpha}=\frac{2 k_{\alpha} E_{T}}{c} \frac{\cosh [2 k D(1+\varsigma)]}{\sinh (2 k D)} .
$$

All the terms in Eq. (A1) are functions of the wave direction $\theta$, and all are kinematic (i.e., energy terms are divided by water density). Therefore, the atmospheric work done on the water is $\rho_{w} S_{\theta \mathrm{in}}$.

The wave frequency $\sigma_{\theta}$ at angle $\theta$ is found by solving the following (Mellor et al. 2008):

$$
\begin{aligned}
\frac{\partial \sigma_{\theta}}{\partial t} & +\left(\bar{c}_{g \alpha}+\bar{u}_{A \alpha}\right) \frac{\partial \sigma_{\theta}}{\partial x_{\alpha}} \\
& =-\frac{\partial \sigma_{\theta}}{\partial k}\left(\frac{k_{\alpha} k_{\beta}}{k} \frac{\partial \bar{u}_{A \alpha}}{\partial x_{\beta}}\right)+\frac{\partial \sigma_{\theta}}{\partial D}\left(\frac{\partial D}{\partial t}+\bar{u}_{A \alpha} \frac{\partial D}{\partial x_{\alpha}}\right)+\Re,
\end{aligned}
$$

again with the appropriate implied summations over $\alpha$ and $\beta$. Here, we have $\partial \sigma_{\theta} / \partial k=\bar{c}_{g}, \partial \sigma_{\theta} / \partial D=\left(\sigma_{\theta} / D\right)(n-12)$ and $n=1 / 2+k D / \sinh (2 k D)$. In the regions of $\theta$ where the waves are wind driven, $\Re$ is an additional source term:

$$
\Re=\sigma_{p}\left(\sigma_{p}-\sigma_{\theta}\right) f_{\mathrm{spr}}^{1 / 2},
$$

where $f_{\mathrm{spr}}=S_{\theta \mathrm{in}} / \int_{-\pi / 2}^{\pi / 2} S_{\theta \mathrm{in}} d \theta$ is the spreading function.

\section{b. The hydrodynamic model}

\section{1) Continuity And MOMEnTUM EQuATIONS}

The hydrodynamics model is based on FVCOM with the inclusion of the wave-current interaction processes proposed by Mellor (2003), Mellor et al. (2008), and Mellor (2015) (noted in section 1). FVCOM solves the same model equations as the Princeton Ocean Model (POM; Mellor 2004) but uses the finite-volume method rather than the finite-difference method used by POM. In the sigma coordinate system, the momentum and continuity equations are given by the following (Chen et al. 2003):

$$
\begin{gathered}
\frac{\partial \hat{\eta}}{\partial t}+\frac{\partial D u}{\partial x}+\frac{\partial D v}{\partial y}+\frac{\partial \omega}{\partial \varsigma}=0, \\
\frac{\partial u D}{\partial t}+\frac{\partial u^{2} D}{\partial x}+\frac{\partial u v D}{\partial y}+\frac{\partial u \omega}{\partial \varsigma}-f v D \\
=-g D \frac{\partial \hat{\eta}}{\partial x}-\frac{g D}{\rho_{0}}\left[\frac{\partial}{\partial x}\left(D \int_{\varsigma}^{0} \rho d \varsigma^{\prime}\right)+\sigma \rho \frac{\partial D}{\partial x}\right] \\
+D F_{u}+\frac{1}{D} \frac{\partial\left(\tau_{t x}+\tau_{p x}\right)}{\partial \varsigma}+R_{x}, \quad \text { and } \\
\frac{\partial v D}{\partial t}+\frac{\partial u v D}{\partial x}+\frac{\partial v^{2} D}{\partial y}+\frac{\partial v \omega}{\partial \varsigma}+f u D \\
=-g D \frac{\partial \hat{\eta}}{\partial y}-\frac{g D}{\rho_{0}}\left[\frac{\partial}{\partial y}\left(D \int_{\varsigma}^{0} \rho d s^{\prime}\right)+\sigma \rho \frac{\partial D}{\partial y}\right] \\
+D F_{v}+\frac{1}{D} \frac{\partial\left(\tau_{t y}+\tau_{p y}\right)}{\partial \varsigma}+R_{y} .
\end{gathered}
$$

The $F_{u}$ and $F_{v}$ are horizontal momentum diffusion terms, calculated by the Smagorinsky eddy parameterization method (Smagorinsky 1963). The vector $\left(\tau_{t x}, \tau_{t y}\right)=K_{m} / D(\partial u / \partial \varsigma, \partial v / \partial \varsigma)$ is the turbulent-viscous part of the wind stress or skin friction. The Stokes drift velocity (definition in section 3a) is not accounted for in vertical mixing (Mellor 2005), so that in the calculation of $\left(\tau_{t x}, \tau_{t y}\right)$ it is subtracted from the velocity $(u, v)$.

The additional terms due to waves are the threedimensional wind stress induced by form drag $\left(\tau_{p x}, \tau_{p y}\right)$ and the wave radiation stress $\left(R_{x}, R_{y}\right)$ (Mellor et al. 2008):

$$
\left(\tau_{p x}, \tau_{p y}\right)=\frac{\cosh [2 k D(1+\varsigma)]}{2 \pi \sinh (2 k D)} \int_{0}^{2 \pi} P_{w 0} \sin \phi \frac{\partial \eta}{\partial x_{\alpha}} d \theta
$$


with $\tau_{p x}$ given by the RHS with $\alpha=1$; that is, $\phi$ is the water elevation caused by the waves, with $x_{\alpha}=x_{1}=x$. Similarly, $\tau_{p y}$ is given by the RHS $a$ the amplitude and $\phi=k(x \cos \theta+y \sin \theta)-\omega t$ the with $\alpha=2$, that is, with $x_{\alpha}=x_{2}=y$. Here $\eta=a \cos$ phase:

$$
\begin{aligned}
R_{x} & =-D\left[\frac{\partial S_{x x}(\varsigma)}{\partial x}+\frac{\partial S_{x y}(\varsigma)}{\partial y}\right]+\gamma\left[\frac{\partial D}{\partial x} \frac{\partial S_{x x}(\varsigma)}{\partial \gamma}+\frac{\partial D}{\partial y} \frac{\partial S_{x y}(\varsigma)}{\partial \gamma}\right], \quad \text { and } \\
R_{y} & =-D\left[\frac{\partial S_{y x}(\varsigma)}{\partial x}+\frac{\partial S_{y y}(\varsigma)}{\partial y}\right]+\gamma\left[\frac{\partial D}{\partial x} \frac{\partial S_{y x}(\varsigma)}{\partial \varsigma}+\frac{\partial D}{\partial y} \frac{\partial S_{y y}(\varsigma)}{\partial \varsigma}\right] \\
S_{x x}(\varsigma) & =E_{T} \frac{k\{\cosh [2 k(1+\varsigma) D]+1\}}{\sinh (2 k D)} \cos ^{2} \theta-E_{T} \frac{k\{\cosh [2 k(1+\varsigma) D]+1\}}{\sinh (2 k D)}+E_{D} \\
S_{y y}(\varsigma) & =E_{T} \frac{k\{\cosh [2 k(1+\varsigma) D]+1\}}{\sinh (2 k D)} \sin ^{2} \theta-E_{T} \frac{k\{\cosh [2 k(1+\varsigma) D]+1\}}{\sinh (2 k D)}+E_{D} \\
S_{x y}(\varsigma) & =S_{y x}(\varsigma)=E_{T} \frac{k\{\cosh [2 k(1+\varsigma) D]+1\}}{\sinh (2 k D)} \sin \theta \cos \theta
\end{aligned}
$$

The $E_{D}(s)$ is a modified delta function, equal to 0 if $s \neq 0$, and $\int_{-1}^{0} E_{D} D d s=E_{\theta} / 2$.

\section{2) Vertical turbulent Closure EQUATIONS}

The vertical eddy viscosity coefficient $K_{m}$ is calculated using the Mellor and Yamada (1982) level-2.5 turbulent closure model with form drag taken into consideration. The simplified equations are given by

$$
\begin{gathered}
\frac{\partial q^{2} D}{\partial t}+\frac{\partial q^{2} u D}{\partial x}+\frac{\partial q^{2} v D}{\partial y}+\frac{\partial q^{2} \omega}{\partial \varsigma}=2 D\left(P_{b}-\varepsilon\right)+\frac{1}{D} \frac{\partial}{\partial \varsigma}\left(K_{q} \frac{\partial q^{2}}{\partial \varsigma}\right)+2\left(\tau_{p x} \frac{\partial u}{\partial \varsigma}+\tau_{p y} \frac{\partial v}{\partial \varsigma}+\tau_{t x} \frac{\partial u}{\partial \varsigma}+\tau_{t y} \frac{\partial v}{\partial \varsigma}\right)+F_{q}, \quad \text { and } \\
\frac{\partial q^{2} l D}{\partial t}+\frac{\partial q^{2} l u D}{\partial x}+\frac{\partial q^{2} l v D}{\partial y}+\frac{\omega}{D} \frac{\partial q^{2} l \omega}{\partial \varsigma}=l E_{1} D\left(P_{b}-\frac{\tilde{W}}{E_{1}} \varepsilon+\tau_{p x} \frac{\partial u}{\partial \varsigma}+\tau_{p y} \frac{\partial v}{\partial \varsigma}+\tau_{t x} \frac{\partial u}{\partial \varsigma}+\tau_{t y} \frac{\partial v}{\partial \varsigma}\right)+\frac{1}{D} \frac{\partial}{\partial \varsigma}\left(K_{q} \frac{\partial q^{2} l}{\partial \varsigma}\right)+D F_{l},
\end{gathered}
$$

where $P_{b}=\left[g K_{h}(\partial \rho / \partial D \varsigma)\right] / \rho_{0}$ is the buoyancy production term of turbulent energy; $\tilde{W}=1+E_{2} l^{2} /(\kappa L)^{2}$ is a wall proximity function, with $\kappa=0.4$ and $L^{-1}=$ $(\hat{\eta}-z)^{-1}+(H+z)^{-1}$; and $E_{1}$ and $E_{2}$ are empirical constants. The turbulent kinetic energy and macroscale equations are closed by the relationships $K_{m}=l q S_{m}$ and $K_{q}=0.2 l q$. More details can be found in Mellor and Yamada (1982) and Galperin et al. (1988).

The turbulent kinetic flux $q^{2}$ induced by surface wave dissipation (Mellor and Blumberg 2004) is given by

$$
\frac{\partial q^{2}}{\partial z}=\frac{2 \alpha_{C B} u_{\tau s}^{3}}{K_{q}} ; \quad l=\max \left(\kappa z_{w}, l z\right) \quad \text { at } \quad z=\varsigma(x, y, t),
$$

where $\alpha_{C B}=15\left(c_{p} / u_{*}\right) \exp \left[-\left(0.04 c_{p} / u_{*}\right)^{4}\right]$ is a parameter related to wave age $c_{p} / u^{*} ; c_{p}$ is the phase speed of the wave at the dominant frequency; $u^{*}=30 u_{\tau s}$ is the air friction velocity; and $z_{w}=0.85 H_{s}$ is the wave-related roughness height. The bottom wave dissipation (Mellor 2013), given by 


$$
\frac{\partial q^{2}}{\partial z}=\int_{-\pi}^{-\pi} S_{\theta \mathrm{Bdis}} d \theta ; \quad l=0 \quad \text { at } \quad z=-H(x, y),
$$

is added at the bottom boundary.

\section{3) BOTTOM BOUNDARY CONDITION FOR} WAVE-CURRENT-SEDIMENT INTERACTION

According to Madsen (1994), the bottom stress is enhanced by the nonlinear interaction of waves and currents in the wave boundary layer. The maximum instantaneous shear stress for the combined flow $\tau_{w c}$ is the vector sum of the time average of the instantaneous shear stress of the current $\tau_{c}$ and the maximum shear stress associated with the wave $\boldsymbol{\tau}_{w m}$ :

$$
\boldsymbol{\tau}_{w c}=\boldsymbol{\tau}_{c}+\boldsymbol{\tau}_{w m} .
$$

Replacing the shear stresses with the magnitude of the shear velocities, the equation above can be transformed into (Madsen 1994)

$$
u_{*_{c w}}^{2}=C_{\mu} u_{*_{w m}}^{2},
$$

where

$$
C_{\mu}=\left[1+2\left(\frac{u_{*_{c}}}{u_{*_{w m}}}\right)^{2} \cos \theta_{w c}+\left(\frac{u_{*_{c}}}{u_{*_{w m}}}\right)^{4}\right]^{1 / 2}
$$

A wave and current friction factor $f_{\mathrm{cw}}$ is introduced to relate $\tau_{w m}$ to the magnitude of the bottom wave orbital velocity $u_{b}$ :

$$
\tau_{w m}=\rho u_{*_{w m}}^{2}=(1 / 2) f_{c w} u_{b}^{2},
$$

where

$$
f_{c w}=\left\{\begin{array}{ll}
C_{\mu} \exp \left[7.02\left(\frac{C_{\mu} u_{b}}{k_{N} \sigma_{r}}\right)^{-0.078}-8.82\right], & 0.2<\frac{C_{\mu} u_{b}}{k_{N} \sigma_{r}}<10^{2} \\
C_{\mu} \exp \left[5.61\left(\frac{C_{\mu} u_{b}}{k_{N} \sigma_{r}}\right)^{-0.109}-7.30\right], & 10^{2}<\frac{C_{\mu} u_{b}}{k_{N} \sigma_{r}}<10^{4}
\end{array} .\right.
$$

With $u *_{w c}$ and the current velocity $u_{c r}$ at a given elevation $z_{r}$ above the sea bed, the current shear velocity $u *_{c}$ can be written as follows (Madsen 1994):

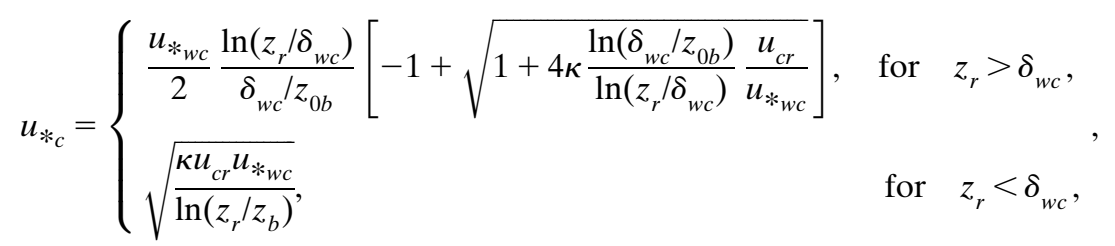

where $z_{0 b}=k_{N} / 30$ is the bottom roughness length, set to 0.001 in this study, and the wave boundary layer thickness $\delta_{w c}$ is defined by

$$
\delta_{w c}=\left\{\begin{array}{lll}
2 \kappa u_{w c} / \sigma_{r} & \text { for } & \frac{C_{\mu} u_{b r}}{k_{N} \sigma_{r}}>8 \\
k_{N} & \text { for } & \frac{C_{\mu} u_{b r}}{k_{N} \sigma_{r}}<8
\end{array} .\right.
$$

The combined wave-current bottom stress is obtained through iteration. First, $C_{\mu}$ is assumed to be 1.0 to obtain an initial guess for $u_{*_{w m}}$ from Eq. (A16) and for $u_{*_{c}}$ from Eq. (A20). After one iteration, $C_{\mu}$ is updated from Eq. (A16). This procedure is repeated until $f_{\mathrm{cw}}$ reaches a stable value to a precision of two significant digits.

\section{c. The sediment model}

UNSW-Sed was used for the suspended-sediment simulation. The governing equation for the suspended sediment is concentration based and includes the physical processes of advection, diffusion, settling, erosion, and deposition of suspended sediments: 


$$
\begin{array}{r}
\frac{\partial}{\partial t}(C D)+\frac{\partial}{\partial x}(C u D)+\frac{\partial}{\partial y}(C v D)+\frac{\partial}{\partial \sigma}\left[C\left(w+w_{s}\right)\right] \\
=\frac{\partial}{\partial x}\left(H A_{h} \frac{\partial C}{\partial x}\right)+\frac{\partial}{\partial y}\left(H A_{h} \frac{\partial C}{\partial y}\right)+\frac{\partial}{\partial \varsigma}\left(\frac{K_{m}}{D} \frac{\partial C}{\partial \varsigma}\right) .
\end{array}
$$

Here, $w_{s}$ is the particle settling velocity, which is unaffected by the transformation from a Cartesian coordinate system to the sigma coordinate system.

By considering the contribution of SSC in the nepheloid layer (Wang 2002), the seawater density can be calculated as

$$
\rho=\rho_{w}+\left(1-\frac{\rho_{w}}{\rho_{s}}\right) C .
$$

A flux Richardson number was introduced by Wang (2002) into the bottom friction coefficient $C_{d}$ to include the effect of a sediment-induced bottom boundary layer in the model, giving

$$
C_{d}=\left[\frac{1}{\kappa /\left(1+A R_{f}\right)} \ln \left(\frac{H+z_{b}}{z_{0}}\right)\right]^{-2},
$$

where $R_{f}$ is the flux Richardson number, indicating vertical density stratification in the Mellor-Yamada level-2 approximation. The $A$ is an empirical constant ranging from 6.8 to 14.7, independent of flow state and $R_{f}$. The $A$ has been set to be various different values in previous studies (Taylor and Dyer 1977; Adams and Weatherly 1981; Glenn and Grant 1987; Wang 2002; Conley et al. 2008). The $z_{0}$ and $z_{b}$ are the bottom roughness and the near-bottom layer thickness, respectively.

For the suspended-sediment flux, the surface condition is

$$
\frac{K_{m}}{D} \frac{\partial C}{\partial \varsigma}-C w_{s}=0, \quad \varsigma \rightarrow 0,
$$

and the bottom condition is

$$
\frac{K_{m}}{D} \frac{\partial C}{\partial \varsigma}-C w_{s}=E_{b}, \quad \varsigma \rightarrow 1 .
$$

The $E_{b}$ can be expressed as follows (Ariathurai and Krone 1976):

$$
E_{b}=\left\{\begin{array}{lll}
E_{0}\left(\frac{\left|\tau_{b}\right|}{\tau_{c}}-1\right), & \text { if } & \left|\tau_{b}\right| \geq \tau_{c} \\
C_{b} w_{s}\left(\frac{\left|\tau_{b}\right|}{\tau_{c}}-1\right), & \text { if } & \left|\tau_{b}\right|<\tau_{c}
\end{array} .\right.
$$

\section{REFERENCES}

Adams, C. E., Jr., and G. L. Weatherly, 1981: Some effects of suspended sediment stratification on an oceanic bottom boundary layer. J. Geophys. Res., 86, 4161-4172, https://doi.org/ 10.1029/JC086iC05p04161.

Allen, J. I., P. J. Somerfield, and F. J. Gilbert, 2007: Quantifying uncertainty in high-resolution coupled hydrodynamicecosystem models. J. Mar. Sci., 64, 3-14, https://doi.org/ 10.1016/j.jmarsys.2006.02.010.

Ardhuin, F., N. Suzuki, J. C. McWilliams, and H. Aiki, 2017: Comments on "A combined derivation of the integrated and vertically resolved, coupled wave-current equations." J. Phys. Oceanogr., 47, 2377-2385, https://doi.org/10.1175/ JPO-D-17-0065.1.

Ariathurai, R., and R. B. Krone, 1976: Finite element model for cohesive sediment transport. J. Hydraul. Div., 102, 323-338.

Bolaños, R., J. M. Brown, and A. J. Souza, 2014: Wave-current interactions in a tide dominated estuary. Cont. Shelf Res., 87, 109-123, https://doi.org/10.1016/j.csr.2014.05.009.

Booij, N., R. C. Ris, and L. H. Holthuijsen, 1999: A thirdgeneration wave model for coastal regions: 1 . Model description and validation. J. Geophys. Res., 104, 7649-7666, https://doi.org/10.1029/98JC02622.

Chen, C., H. Liu, and R. C. Beardsley, 2003: An unstructured grid, finite volume, three-dimensional, primitive equations ocean model: Application to coastal ocean and estuaries. J. Atmos. Oceanic Technol., 20, 159-186, https://doi.org/10.1175/ 1520-0426(2003)020<0159:AUGFVT>2.0.CO;2.

Choi, J. -K., Y. J. Park, J. H. Ahn, H.-S. Lim, J. Eom, and J. -H Ryu, 2012: GOCI, the world's first geostationary ocean color observation satellite, for the monitoring of temporal variability in coastal water turbidity. J. Geophys. Res., 117, C09004, https://doi.org/10.1029/2012JC008046.

Conley, D. C., and D. L. Inman, 1992: Field observation of the fluid-granular boundary layer under near-breaking waves. J. Geophys. Res., 97, 9631-9643, https://doi.org/10.1029/ 92JC00227.

—, and R. A. Beach, 2003: Cross-shore sediment transport partitioning in the nearshore during a storm event. J. Geophys. Res., 108, 3065, https://doi.org/10.1029/2001JC001230.

— , S. Falchetti, I. P. Lohmann, and M. Brocchini, 2008: The effects of flow stratification by non-cohesive sediment on transport in high-energy wave-driven flows. J. Fluid Mech., 610, 43-67, https://doi.org/10.1017/S0022112008002565.

Ding, Y., H. Yu, X. Bao, K. Liang, C. Wang, and W. Wang, 2011: Numerical study of the barotropic responses to a rapidly moving typhoon in the East China Sea. Ocean Dyn., 61, 1237, https://doi.org/10.1007/s10236-011-0436-1.

Donelan, M. A., J. Hamilton, and W. H. Hui, 1985: Directional spectra of wind-generated waves. Philos. Trans. Roy. Soc. London, 315B, 509-562, https://doi.org/10.1098/ rsta.1985.0054.

Dufois, F., R. Verney, P. Le Hir, and F. Dumas, 2014: Impact of winter storms on sediment erosion in the Rhone River prodelta and fate of sediment in the Gulf of Lion (northwestern Mediterranean Sea). Cont. Shelf Res., 72, 57-72, https://doi.org/ 10.1016/j.csr.2013.11.004.

Editorial Board of Annals of Bays in China, 1993: Annals of Bays in China. Vol. 4. China Ocean Press, 448 pp.

First Institute of Oceanography, 1984: Natural Environment of Jiaozhou Bay (in Chinese). Ocean Press, 286 pp. 
Galperin, B., L. H. Kantha, S. Hassid, and A. Rosati, 1988: A quasi-equilibrium turbulent energy model for geophysical flows. J. Atmos. Sci., 45, 55-62, https://doi.org/10.1175/ 1520-0469(1988)045<0055:AQETEM > 2.0.CO;2.

Gao, G. D., X. H. Wang, and X. W. Bao, 2014: Land reclamation and its impact on tidal dynamics in Jiaozhou Bay, Qingdao, China. Estuarine Coastal Shelf Sci., 151, 285-294, https://doi.org/ 10.1016/j.ecss.2014.07.017.

,,--- D D. H. Song, X. P. Lin, and L. L. Qiao, 2018: The impacts of land reclamation on suspended-sediment dynamics in Jiaozhou Bay, Qingdao, China. Estuarine Coastal Shelf Sci. 206, 61-75, https://doi.org/10.1016/j.ecss.2017.01.012.

Glenn, S. M., and W. D. Grant, 1987: A suspended sediment stratification correction for combined wave and current flows. J. Geophys. Res., 92, 8244-8264, https://doi.org/10.1029/JC092iC08p08244.

Graber, H. C., R. C. Beardsley, and W. D. Grant, 1989: Stormgenerated surface waves and sediment resuspension in the East China and Yellow Seas. J. Phys. Oceanogr., 19, 1039-1059, https://doi.org/10.1175/1520-0485(1989) $019<1039$ :SGSWAS $>2.0$.CO 2 .

Korea Ocean Satellite Center, 2015: GDPS ver. 1.4 user's manual. Korea Institute Of Ocean Science and Technology Rep., 108 pp., http://kosc.kiost.ac.kr/eng/p30/kosc p34.html.

Lane, E. M., J. M. Restrepo, and J. C. McWilliams, 2007: Wavecurrent interaction: A comparison of radiation-stress and vortex-force representations. J. Phys. Oceanogr., 37, 11221141, https://doi.org/10.1175/JPO3043.1.

Li, L., X. H. Wang, F. Andutta, and D. Williams, 2014: Effects of mangroves and tidal flats on suspended-sediment dynamics: Observational and numerical study of Darwin Harbour, Australia. J. Geophys. Res. Oceans, 119, 5854-5873, https:// doi.org/10.1002/2014JC009987.

Longuet-Higgins, M. S., and R. W. Stewart, 1964: Radiation stresses in water waves; a physical discussion, with applications. Deep-Sea Res. Oceanogr. Abstr., 11, 529-562, https:// doi.org/10.1016/0011-7471(64)90001-4.

Lou, J., D. J. Schwab, D. Beletsky, and N. Hawley, 2000: A model of sediment resuspension and transport dynamics in southern Lake Michigan. J. Geophys. Res., 105, 6591-6610, https:// doi.org/10.1029/1999JC900325.

Madsen, O. S., 1994: Spectral wave-current bottom boundary layer flows. Proc. 24th Int. Conf. on Coastal Engineering Research Council, Kobe, Japan, American Society of Civil Engineering, 384-398.

Mehta, A. J., and W. H. McAnally, 2008: Fine-grained sediment transport. Sedimentation Engineering: Processes, Management, Modeling, and Practice, M. H. Garcia, Ed., American Society of Civil Engineering, 253-307.

Mellor, G. L., 2003: The three-dimensional current and surface wave equations. J. Phys. Oceanogr., 33, 1978-1989, https://doi. org/10.1175/1520-0485(2003)033<1978:TTCASW>2.0.CO;2.

_ 2004: Users guide for a three-dimensional, primitive equation, numerical ocean model. Princeton University Program in Atmospheric and Oceanic Sciences Rep., 56 pp., http://jes.apl.washington.edu/modsims_two/usersguide0604.pdf.

- 2005: Some consequences of the three-dimensional current and surface wave equations. J. Phys. Oceanogr., 35, 22912298, https://doi.org/10.1175/JPO2794.1.

_ 2013: Pressure-slope momentum transfer in ocean surface boundary layers coupled with gravity waves. J. Phys. Oceanogr., 43, 2173-2184, https://doi.org/10.1175/JPO-D-13-068.1.
- 2015: A combined derivation of the integrated and vertically resolved, coupled wave-current equations. J. Phys. Oceanogr., 45, 1453-1463, https://doi.org/10.1175/JPO-D-14-0112.1.

— , and T. Yamada, 1982: Development of a turbulence closure model for geophysical fluid problems. Rev. Geophys., 20, 851-875, https://doi.org/10.1029/RG020i004p00851.

- , and A. Blumberg, 2004: Wave breaking and ocean surface layer thermal response. J. Phys. Oceanogr., 34, 693-698, https://doi.org/10.1175/2517.1.

— M. A. Donelan, and L.-Y. Oey, 2008: A surface wave model for coupling with numerical ocean circulation models. J. Atmos. Oceanic Technol., 25, 1785-1807, https://doi.org/ 10.1175/2008JTECHO573.1.

Murphy, A. H., 1988: Skill score based on the mean square error and their relationship to the correlation coefficient. Mon. Wea. Rev., 116, 2417-2424, https://doi.org/10.1175/1520-0493(1988)116<2417: SSBOTM $>2.0 . \mathrm{CO} ; 2$

Palanques, A., P. Puig, J. Guillén, X. Durrieu de Madron, M. Latasa, R. Scharek, and J. Martin, 2011: Effects of storm events on the shelf-to-basin sediment transport in the southwestern end of the Gulf of Lion (northwestern Mediterranean). Nat. Hazards Earth Syst. Sci., 11, 843-850, https://doi.org/ 10.5194/nhess-11-843-2011.

Pierson, W. J., Jr., and L. Moskowitz, 1964: A proposed spectral form for fully developed wind seas based on the similarity theory of S. A. Kitaigoradskii. J. Geophys. Res., 69, 5181-5190, https://doi.org/10.1029/JZ069i024p05181.

Porter-Smith, R., P. T. Harris, O. B. Andersen, R. Coleman, D. Greenslade, and C. J. Jenkins, 2004: Classification of the Australian continental shelf based on predicted sediment threshold exceedance from tidal currents and swell waves. Mar. Geol., 211, 1-20, https://doi.org/10.1016/ j.margeo.2004.05.031.

Ryu, J.-H., H.-J. Han, S. Cho, Y.-J. Park, and Y. H. Ahn, 2012: Overview of Geostationary Ocean Color Imager (GOCI) and GOCI Data Processing System (GDPS). Ocean Sci. J., 47, 223-233, https://doi.org/10.1007/s12601-012-0024-4.

Sheng, Y. P., and T. Liu, 2011: Three-dimensional simulation of wave-induced circulation: Comparison of three radiation stress formulations. J. Geophys. Res., 116, C05021, https://doi.org/ 10.1029/2010JC006765.

Smagorinsky, J., 1963: General circulation experiments with the primitive equations: I. The basic experiment. Mon. Wea. Rev., 91, 99-164, https://doi.org/10.1175/1520-0493(1963)091<0099: GCEWTP $>2.3 . \mathrm{CO} ; 2$.

Smith, J. A., 2006: Wave-current interactions in finite depth. J. Phys. Oceanogr., 36, 1403-1419, https://doi.org/10.1175/JPO2911.1.

Song, D., and X. H. Wang, 2013: Suspended sediment transport in the Deepwater Navigation Channel, Yangtze River Estuary, China, in the dry season 2009: 2. Numerical simulations. J. Geophys. Res. Oceans, 118, 5568-5590, https://doi.org/ 10.1002/jgrc.20411.

Tang, Y. M., and R. Grimshaw, 1996: The effect of wind-wave enhancement of bottom stress on the circulation induced by tropical cyclones on continental shelves. J. Geophys. Res., 101, 22 705-22 714, https://doi.org/10.1029/96JC02002.

Taylor, P. A., and K. R. Dyer, 1977: Theoretical models of flow near the bed and their implications for sediment transport. Marine Modeling, E. D. Goldberg et al., Eds., The Sea-Ideas and Observations on Progress in the Study of the Seas, Vol. 6, John Wiley and Sons, 579-601. 
U.S. Naval Oceanographic Office, 1983: DBDB5 (Digital Bathymetric Data Base-5 Minute Grid). U.S. Naval Oceanographic Office Rep., 329 pp

Wang, J., and Y. Shen, 2012: On the development and verification of a parametric parallel unstructured-grid finite-volume wind wave model for coupling with ocean circulation models. Environ. Modell. Software, 37, 179-192, https://doi.org/10.1016/ j.envsoft.2012.03.019.

Wang, X. H., 2002: Tide-induced sediment resuspension and the bottom boundary layer in an idealized estuary with a muddy bed. J. Phys. Oceanogr., 32, 3113-3131, https://doi.org/10.1175/ 1520-0485(2002)032<3113:TISRAT>2.0.CO;2.

, N. Pinardi, and V. Malicic, 2007: Sediment transport and resuspension due to combined motion of waves and currents in the northern Adriatic Sea during a Bora event in January, 2001. Cont. Shelf Res., 27, 613-633, https://doi.org/10.1016/ j.csr.2006.10.008.

Wang, Y. H., W. Frank Bohlen, and J. O'Donnell, 2000: Storm enhanced bottom shear stress and associated sediment entrainment in a moderate energetic estuary. J. Oceanogr., 56, 311-317, https://doi.org/10.1023/A:1011155717622.

Wang, Y. P., S. Gao, J. Jia, Y. Liu, and J. Gao, 2014: Remarked morphological change in a large tidal inlet with low sediment supply. Cont. Shelf Res., 90, 79-95, https://doi.org/10.1016/ j.csr.2014.02.005.

Warner, J. C., C. R. Sherwood, R. P. Signell, C. Harris, and H. G. Arango, 2008: Development of a three-dimensional, regional, coupled wave, current, and sediment-transport model. Comput. Geosci., 34, 1284-1306, https://doi.org/10.1016/ j.cageo.2008.02.012.

Yang, S. L., J. Zhang, and J. Zhu, 2004: Response of suspended sediment concentration to tidal dynamics at a site inside the mouth of an inlet: Jiaozhou Bay (China). Hydrol. Earth Syst. Sci., 8, 170-182, https://doi.org/10.5194/hess-8-170-2004.

Zhong, S. L., Y. P. Wang, S. Gao, Q. Y. Cao, and Y. H. Zhu, 2001: Distribution patterns of nannofossil Gephyrocapsa oceanica in surficial sediments of Jiaozhou Bay, southern Shandong Peninsula, China. Acta Palaeontol. Sin., 40, 505-513. 